\title{
Reversion to regular diet with alternate day fasting can cure grade-I non-alcoholic fatty liver disease (NAFLD) in high-fructose- intake-associated metabolic syndrome
}

Nehal Mohamed Bahgat Gamil ${ }^{1,2^{*}}$ (D), Sahar Mohamed El Agaty ${ }^{1}$, Gehan Khalaf Megahed ${ }^{1}$, Rania Salah Mansour ${ }^{1}$ and Marwa Saad Abdel-Latif ${ }^{1}$

\begin{abstract}
Background: Non-alcoholic fatty liver disease (NAFLD) is an emerging global health problem that accompanied the obesity epidemic and is considered as the hepatic component of metabolic syndrome (MetS). Modification of lifestyle of MetS patients remains the focus to reverse and prevent progression of hepatic steatosis to NAFLD and its worsening to severe forms. The present study investigates the possible curability of metabolic syndrome -associated grade-1 NAFLD merely by alternate day fasting with or without reversion to regular diet in adult male rats. The present study was performed on 66 local strain male rats aged $(6-10 \mathrm{~m}$.) distributed randomly into $\mathrm{C}$ group $(n=12)$, on regular rat diet; and M group $(n=54)$ on high fructose- intake. On the 8th week, then rats were subjected to measurement of BW, BMI, WC, FBG, IPGT, HDL-C, TGs, and liver histopathology, to include MetS rats randomly into four experimental groups for 4 weeks as follows: MS $(n=14) ; \operatorname{MSRD}(n=12) ; \operatorname{MSF}(n=13)$; and $\operatorname{MSRDF}(n=12)$. On the 12th week, all rats were subjected to measurements of BW, BMI, WC, LW, LW/BW, VFW, VFW/BW, FBG, IPGT, Ins., HOMA-IR, HbA1C, TGS, TC, LDL-C, HDL-C, CRP, Alb., bilirubin, ALT, L-MDA, and liver histopathology.
\end{abstract}

Results: On the 8th week, M group developed MerS and grade-I NAFLD with score-4 hepatosteatosis (69\%). On the 12th week, MS group had grade-1 NAFLD with score-4 hepatosteatosis (82\%) with significantly increased Ins., HOMA-IR, HDL-C, LW, LW/BW, L-MDA, ALT, CRP, and significantly decreased Alb. than C rats. Both MSRD and MSF groups had grade-1 NAFLD with score-3 hepatosteatosis (42\%) with significantly decreased Ins., HOMA-IR, TC, LDLC, LW, LW/BW, L-MDA, ALT, CRP, and significantly increased HDL-C and Alb. than MS group. MSRDF rats showed cure of grade-1 NAFLD and significantly decreased LW than other groups and normalized HOMA-IR, HBA1C TC, LDL-C, ALT, and CRP.

Conclusion: One month of alternate-day fasting and regular rat diet could cure grade-I NAFLD associated with Mets due to high fructose intake possibly by attenuating metabolic disorders. These two interventions might be recommended in the management of MetS patients with grade 1-NAFLD disease.

Keywords: Metabolic syndrome, Non-alcoholic fatty liver disease, Hepatic steatosis, Alternate day fasting, Insulin resistance

\footnotetext{
* Correspondence: dr_nehalgamil@med.asu.edu.eg

${ }^{1}$ Medical Physiology Department, Faculty of Medicine, Ain Shams University, Cairo, Egypt

${ }^{2}$ Histology and Cell Biology Department, Faculty of Medicine, Ain Shams University, Cairo, Egypt
}

\section{Springer Open}

(c) The Author(s). 2021 Open Access This article is licensed under a Creative Commons Attribution 4.0 International License, which permits use, sharing, adaptation, distribution and reproduction in any medium or format, as long as you give appropriate credit to the original author(s) and the source, provide a link to the Creative Commons licence, and indicate if changes were made. The images or other third party material in this article are included in the article's Creative Commons licence, unless indicated otherwise in a credit line to the material. If material is not included in the article's Creative Commons licence and your intended use is not permitted by statutory regulation or exceeds the permitted use, you will need to obtain permission directly from the copyright holder. To view a copy of this licence, visit http://creativecommons.org/licenses/by/4.0/. 


\section{Background}

The metabolic syndrome (MetS) is a cluster of risk factors for cardiovascular disease and type 2 diabetes mellitus [1]. The diagnosis of MetS is based on presence of 3 of 5 factors, which include TGs $150 \mathrm{mg} / \mathrm{dL}$ or greater, high-density lipoprotein cholesterol (HDL-C) of less than $40 \mathrm{mg} / \mathrm{dL}$ in men and less than $50 \mathrm{mg} / \mathrm{dL}$ in women, hypertension defined as systolic blood pressure $130 \mathrm{mmHg}$ or greater or diastolic blood pressure 85 $\mathrm{mmHg}$ or greater, hyperglycemia defined as fasting glucose $100 \mathrm{mg} / \mathrm{dL}$ or greater, and increased waist circumference, defined by country and population-specific criteria [1].

The incidence of non-alcoholic fatty liver disease (NAFLD) has been increasing in concert with the rising rates of MetS [2]. Epidemiological data shows that global prevalence of NAFLD in different populations is around $30 \%$ [3]. NAFLD is the most common cause of chronic liver disease worldwide [4]. NAFLD is comprised of nonalcoholic fatty liver (NAFL) and nonalcoholic steatohepatitis (NASH) [5]. NAFL is characterized by steatosis of the liver, involving greater than $5 \%$ of parenchyma, with no evidence of hepatocyte injury [6]. Whereas NASH is a necroinflammatory process whereby the liver cells become injured in a background of steatosis [6]. NASH may progress to fibrosis, cirrhosis, and hepatocellular carcinoma (HCC) $[7,8]$. According to the guidelines of the American Association for the Study of Liver Diseases (AASLD), the definition of NAFLD requires the presence of primary hepatic steatosis diagnosed either by imaging or by histology and no other reasons for secondary hepatic fat accumulation [9]. Within the next 20 years, it is expected that NAFLD will be the major cause of liverrelated morbidity and mortality as well as a leading indication for liver transplantation [10].

The development of NAFLD (i.e., steatosis) results from an increased inflow of free fatty acids (FFA) derived from insulin-resistant adipose tissue, altered hepatic processing of dietary lipids delivered by lipoproteins, increased hepatic de novo lipogenesis, or impaired lipid export out of the hepatocytes [4]. Also, alterations in the production and secretion of adipokines and inflammatory cytokines due to adipose tissue dysfunction because of insulin resistance are involved [11]. Moreover, the production of reactive oxygen species, endoplasmic reticulum stress coupled with mitochondrial dysfunction, and the gut microbiota had been recognized as key players in the pathogenesis of NAFLD $[2,12]$.

NAFLD remains asymptomatic in a significant proportion of patients, and the diagnosis is often suspected when liver functions are found abnormal on biochemical testing or hepatic imaging (ultrasonography, computed tomography $[\mathrm{CT}]$, or magnetic resonance imaging [MRI] of liver) suggest fatty liver, when performed for other purposes [13]. Liver biopsy remains the gold standard for diagnostic evaluation of NAFLD [13]. Biopsy not only confirms the diagnosis but provides information on extent of fibrosis and steatosis, necro-inflammation, and architectural distortion [13].

Human fructose consumption is largely driven by added sugars, and the intake of sugar-sweetened beverages generally corresponds to total fructose intake [14]. Several epidemiological studies have evaluated the association between average daily fructose intake and hepatic steatosis [15]. Several factors may potentially contribute to fructose-induced NAFLD, including the induction of the MetS [16].

There is no single intervention that is proven to be fully effective in the treatment and cure of NAFLD [13]. The main goals of treatment are to improve steatosis and to prevent progression of the disease [13]. Intense lifestyle modification and treatment of the risk factors are the cornerstones of disease management [13]. Medical and surgical interventions serve as second-line treatments, or as adjuvants [13]. Both exercise and dietary interventions in isolation or in combination have been shown to improve biochemical and histological parameters of NAFLD [13].

There are two methods of dietary restriction, which are caloric restriction $(\mathrm{CR})$ and intermittent fasting (IMF) [17]. IMF protocols can be grouped into alternate-day fasting (ADF), whole-day fasting, and timerestricted feeding like one-meal-per-day [18]. ADF regimens consist of a "feed day" (ad libitum food intake for $24 \mathrm{~h}$ ) alternated with a "fast day" (complete fast for 24 h), but the overall energy intake is not limited [19]. IMF is a nutritional intervention with significant metabolic effects on the liver that are not yet fully understood.

\section{Methods}

\section{Experimental animals}

This study was approved by the Research Ethics Committee at the Faculty of Medicine, Ain Shams University (The FMASU REC) that operates under Federal Wide Assurance No. FWA 000017585.

The present study was performed on 66 local strain male rats, initially weighing $120-180$ g. Rats were purchased from VACSERA (EGY VAC) (Helwan, Cairo) and were housed in Medical Ain Shams Research Institute (MASRI) Animal House, Faculty of Medicine, Ain Shams University, under standard conditions of boarding at room temperature $22 \pm 4{ }^{\circ} \mathrm{C}$. Rats were kept in plastic cages (3-5 rats/cage) for 2 weeks for acclimatization. Animals were randomly allocated into the following two groups:

Group I; control rat group (C, $n=12)$ : Rats in this group were fed the control diet for 8 weeks. At the end of the 8th week, two rats were scarified for 
histopathological study of the liver; the other 10 rats were continued on the control diet for additional 4 weeks and were studied by the end of the 12 th week.

Group II; metabolic syndrome with liver steatosis rat group (M, $n=54)$ : Metabolic syndrome was induced by high fructose diet besides additional fructose solution (4 $\mathrm{g}$ fructose dissolved in $4 \mathrm{ml}$ distilled water/rat/day) introduced daily by gavage. The high fructose diet and solution was given for 8 weeks. At the end of the 8th week, three rats were scarified for histopathological study of the liver. Blood samples were withdrawn from all rats for laboratory examination, then the proven metabolic syndrome rats $(n=51)$ were randomly allocated into the following four experimental groups:

A. Untreated metabolic syndrome group (MS, $n=14$ ): Rats in this group were continued on high fructose diet and the fructose solution by gavage similar to $\mathrm{M}$ group for additional 4 weeks and were studied at the end of the 12th week.

B. Metabolic syndrome group reverted to regular rat chow (MSRD, $n=12$ ): Rats in this group were reverted to control diet for 4 weeks.

C. Metabolic syndrome group on alternate-day fasting (MSF, $n=13$ ) according to Varady et al. [20]: Rats in this group underwent alternate-day fasting regimen in the form of alternating 24-h periods of ad libitum feeding and fasting (100\% calorie restriction on fast day, ad libitum high fructose diet on feed day with the fructose solution by gavage similar to the $\mathrm{M}$ group) for 4 weeks.

D. Metabolic syndrome group reverted to regular rat chow and on alternate-day fasting (MSRDF, $n=$ 12): Rats in this group underwent alternate-day fasting regimen in the form of alternating 24-h periods of ad libitum feeding and fasting (100\% calorie restriction on fast day, ad libitum control diet on feed day) for 4 weeks.

Control diet: Rats were fed rat chow consisting of corn starch (61\%), Kareish cheese (casein, 20\%), wheat bran (9.5\%), butter (5\%), mineral mixture (3.5\%), and vitamin mixture (1\%) according to Patel et al. [21]. Food was prepared weekly and was kept in the refrigerator and was administrated ad libitum.

High fructose diet: This diet was prepared as the control diet except for corn starch, which was replaced by fructose powder (Fructofin C, manufactured by Danisco Sweeteners Oy, Kotka, Finland), according to Patel et al. [21] to be $61 \%$ fructose powder, $20 \%$ casein, $9.5 \%$ wheat bran, $5 \%$ butter, $3.5 \%$ mineral mixture, and $1 \%$ vitamin mixture; however, the route of administration was modified, where fructose content in the formula was reduced to $40 \%$ instead of $60 \%$ to avoid food aversion and the remaining $20 \%$ was given by gavage according to Bahgat et al. [22]. Adult rats on high fructose diet showed average food intake $\sim 20 \mathrm{~g} / \mathrm{rat} /$ day by the 2 nd-4th week. Thus, $61 \%$ fructose content in the diet formula is $\approx 12 \mathrm{~g} /$ rat, $2 / 3$ of it was given in the diet and the remaining $1 / 3$ ( $4 \mathrm{~g}$ fructose $/ 4 \mathrm{ml}$ distilled water/rat/day) was given by gavage. Food was prepared weekly and was kept in the refrigerator.

At the end of the accommodation period, all rats in the present study were subjected to basal assessment of body weight (BW), body mass index (BMI), waist circumference (WC), fasting blood glucose level (FBG), and intraperitoneal glucose tolerance test (IPGTT). Retroorbital blood samples were taken for determination of serum levels of HDL-C and TGs. Throughout the experiment, all rats were subjected to weekly assessment of $\mathrm{BW}$. At the end of the induction period of metabolic syndrome (8th week), all rats were re-assessed for the same parameters mentioned before. Five randomly selected rats from $\mathrm{C}$ and $\mathrm{M}$ rat groups were scarified for histopathological study of the liver to prove the presence of steatosis.

At the end of the study on the 12th week, 1 day before sacrifice, rats were subjected to estimation of FBG by using GlucoDr SuperSensor ${ }^{\mathrm{rut}}$ test strips and the GlucoDr Super Sensor ${ }^{\text {mi }}$ Meter apparatus (model name AGM2200, manufactured by All Medicus Co., Ltd., KOREA). Glucose tolerance testing was performed according to Zhang et al. [23], using D-glucose stock (Anhydrous glucose A.R) supplied by El-Nasr Pharmaceutical Chemicals; area under the curve (AUC) was calculated according to Matthews et al. [24].

On the day of sacrifice, overnight fasted rats were weighed, placed on its back, fixed on the dissecting table, and the length of the rat was measured from the tip of the nose (while the neck is extended) to the anus to calculate the BMI according to the following equation: Body mass index $(\mathrm{BMI})=$ Body weight $(\mathrm{g}) /$ length $\left(\mathrm{cm}^{2}\right)$ [25], then the measuring tape was carefully placed under the rat and around the transverse plane, directly below the bottom rib of the rib-cage to measure the WC according to Panchal et al. [26].

The rats were anesthetized by intraperitoneal injection of phenobarbitone in a dose of $40 \mathrm{mg} / \mathrm{kg}$ body weight, blood samples were taken in two separate tubes, one containing EDTA for estimation of glycosylated hemoglobin (HbA1C) and the other was centrifuged at $4000 \mathrm{rpm}$ for $20 \mathrm{~min}$ to separate the serum, that was then stored frozen at $-80{ }^{\circ} \mathrm{C}$ for subsequent determination of the other biochemical studies. Visceral fat and liver were excised, washed with $0.9 \%$ saline solution, and dried by filter paper, then they were freshly weighed in the same day using 5-digit precision Metler balance (AE163).The results were expressed as absolute values 
(g) and relative values to the body weight (absolute tissue weight / body weight, g/g).

\section{Biochemical measurements}

HbA1C (BioSystems S.A. Costa Brava, 30.08030 Barcelona (Spain), colorimetric method). Serum TGs (BioMed laboratory, Badr City, Egypt, colorimetric method) according to Fassati and Prencipe [27]. Serum TC (BioMed laboratory, Badr City, Egypt, colorimetric method) according to Tietz [28]. Serum HDL-C (BioMed laboratory, Badr City, Egypt, colorimetric method) according to Young [29]. Serum fasting insulin and C-reactive protein (CRP) (MyBiosource, Inc., USA, enzyme immunoassay (ELISA)). Serum albumin (BioMed laboratory, Badr City, Egypt, colorimetric method) according to Doumas and Biggs [30]. Serum total bilirubin (BioMed laboratory, Badr City, Egypt, colorimetric method) described by Rand and Di Pasqua [31] automated by Golub [32]. Serum alanine transferase (ALT) (BioMed laboratory, Badr City, Egypt, colorimetric method) according to Henry [33]. Liver tissue malondialdehyde (MDA) (Biodiagnostic, Egypt, colorimetric method) according to Satoh [34] and Ohkawa et al. [35]. Calculation of lowdensity lipoprotein cholesterol (LDL-C) according to the following equation: $\mathrm{C}_{\mathrm{LDL}}=\mathrm{C}_{\mathrm{Total}}-\mathrm{C}_{\mathrm{HDL}}-\mathrm{TG} / 5$ [36].

Calculation of insulin resistance (HOMA-IR) score: insulin resistance was calculated by the Homeostasis Model Assessment Score $=($ fasting insulin $(\mu \mathrm{IU} / \mathrm{mL}) \times$ fasting glucose $(\mathrm{mmol} / \mathrm{L}) / 22.5)$ [37]. Serum insulin was converted from $\mathrm{ng} / \mathrm{mL}$, to $\mu \mathrm{IU} / \mathrm{mL}$ by dividing it by 0.0347 [38]. To convert blood glucose to plasma glucose, the values were multiplied by 1.12 [39]. As blood glucose was measured in $\mathrm{mg} / \mathrm{dl}$, it was converted to $\mathrm{mmol} / \mathrm{L}$ by dividing by 18.016. Biochemical analysis was carried out blindly by an expert clinical pathologist.

\section{Histopathological study}

The liver specimens were collected and fixed in 10\% buffered formalin and embedded in paraffin. Five micrometer sections was cut and stained with hematoxylin and eosin (H\&E), periodic acid-Schiff (PAS), and Maison Trichome. Diagnosis and grading of nonalcoholic fatty liver disease (NAFLD) was done according to Mendler et al. [40] in control (C) and metabolic syndrome (M) groups at the end of 8th week of the study; and in all studied groups 4 weeks later at the end of the study. Histopathology was carried out blindly by an expert histopathologist.

\section{Statistical analysis}

All statistical data and significance tests were performed by using Statistical program for Social Science (SPSS Inc.) version 20 according to Armitage and Berry [41]. Differences in the same group were determined by
Student's " $t$ " test for paired data, differences between 2 groups were compared by independent sample " $t$ " test, and differences between all 5 groups were compared by one-way ANOVA with least significant difference test (LSD), a probability of $P<0.05$ was considered statistically significant. Correlation coefficients were calculated by linear regression analysis (ranking data directly or indirectly) using the least square method. A probability of $P<0.05$ was considered statistically significant. All results were expressed as mean \pm SEM.

\section{Results \\ Eighth week versus initial results of metabolic syndrome (M) and control (C) groups:}

The 8th week values of BW, BMI, and WC were significantly higher than their corresponding initial values in both $C(P<0.001, P<0.005, P<0.005$ respectively $)$ and M groups $(P<0.001)$ (Table 1$)$

Eighth week values of the blood glucose levels during IPGTT at $60 \mathrm{~min}, 90 \mathrm{~min}$, and $120 \mathrm{~min}$, and AUC were significantly increased in $\mathrm{C}$ rats compared to their corresponding initial values $(P<0.05, P<0.05, P<0.01, P<$ 0.05 respectively). For $M$ group, the $8^{\text {th }}$ week values of FBG, blood glucose levels during IPGTT at $30 \mathrm{~min}, 60$ min, $90 \mathrm{~min}$, and $120 \mathrm{~min}$, PG and AUC were significantly increased in $\mathrm{M}$ group compared to their corresponding initial values $(P<0.001)$ (Fig. 1); both $C$ and $M$ groups presented a significantly higher serum level of TGs $(P<0.005, P<0.001$ respectively) along with a significantly lower HDL-C $(P<0.001)$ in the 8th week compared to their corresponding initial values.

The initial values of BW, BMI, WC, FBG, IPGTT, PG, AUC, and serum levels of TGs and HDL-C were insignificantly different between $\mathrm{C}$ and $\mathrm{M}$ groups. After 8 weeks of high fructose diet, $M$ rats exhibited a significantly higher values of WC; blood glucose levels (measured during IPGTT) at $30 \mathrm{~min}$, and $120 \mathrm{~min}$; PG, AUC associated with a significant lower serum levels of HDL$\mathrm{C}$ in comparison to $\mathrm{C}$ group $(P<0.05)$ (Figs. 1 and 2$)$.

\section{Final versus 8th week results of C, MS, MSRD, MSF, and MSRDF}

$\mathrm{BW}$ and BMI were not significantly changed, whereas WC was significantly increased in the $C$ and MS groups in comparison to their corresponding 8th week's values $(P<0.05, P<0.01$, respectively). BW and WC were significantly increased in metabolic syndrome group reverted to regular rat chow (MSRD) group compared to their corresponding 8 th week's values $(P<0.05)$. However, BW, BMI, and WC were significantly decreased in metabolic syndrome group on alternate-day fasting (MSF) group $(P<0.001, P<0.001, P<0.005$ respectively) and MSRDF $(P<0.001)$ groups (Table 2$)$. 
Table 1 The initial and $8^{\text {th }}$ week anthropometric and lipid parameters in control and metabolic syndrome groups

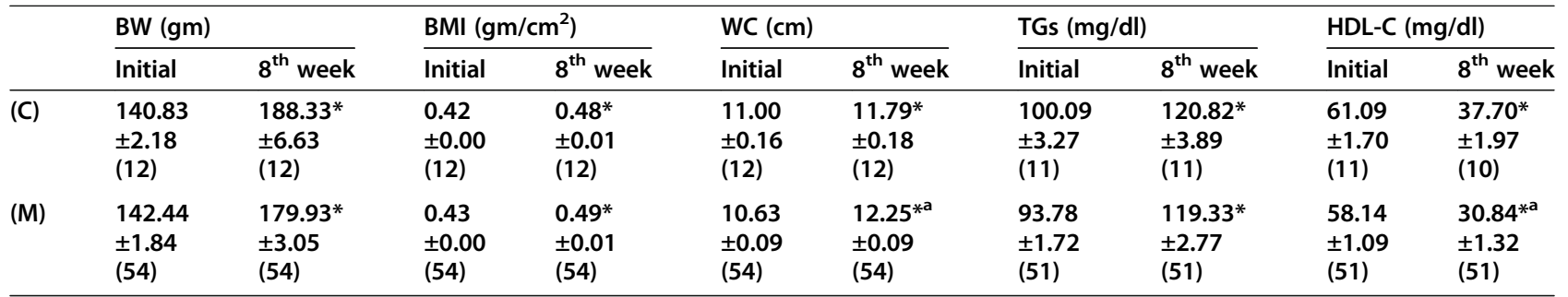

M, metabolic syndrome group; C, control group; BW, body weight; BMI, body mass index; WC, waist circumference; TGs, triglycerides; HDL-C, high density lipoprotein cholesterol

In the parenthesis is the number of observations

Data are expressed as mean \pm SEM

*: Significance from initial value, by Student's " $t$ " test for paired data, at $\mathrm{P} \leq 0.05$

a: Significance from control group, by Student's " $t$ " test for un-paired data, at $P \leq 0.05$

Compared to 8 th week values, serum TGs were significantly decreased in $C$ group $(P<0.001)$, but significantly increased in MS group $(P<0.05)$, but showed significant decrease in MSF group $(P<0.01)$ and insignificant change in MSRD and MSRDF groups. On the other hand, HDL-C showed significant increase in C, MSRD, MSF, and MSRDF groups $(P<0.001, P<0.05, P<0.01$, $P<0.005$ respectively) with insignificant change in MS group (Table 2).
Compared to 8th week values, final FBG, blood glucose levels during IPGTT at $30 \mathrm{~min}, 60 \mathrm{~min}, 90 \mathrm{~min}$, and 120 min; PG; and AUC; all were not significantly changed in the $C$ group. The MS group exhibited a significantly lower final levels of blood glucose during IPGTT at $60 \mathrm{~min}, 90 \mathrm{~min}$, and $120 \mathrm{~min}$, along with a significant decrease in AUC versus their corresponding 8th week's values $(P<0.05, P<0.001, P<0.005, P<$ 0.005 respectively). Although, alternate day fasting alone

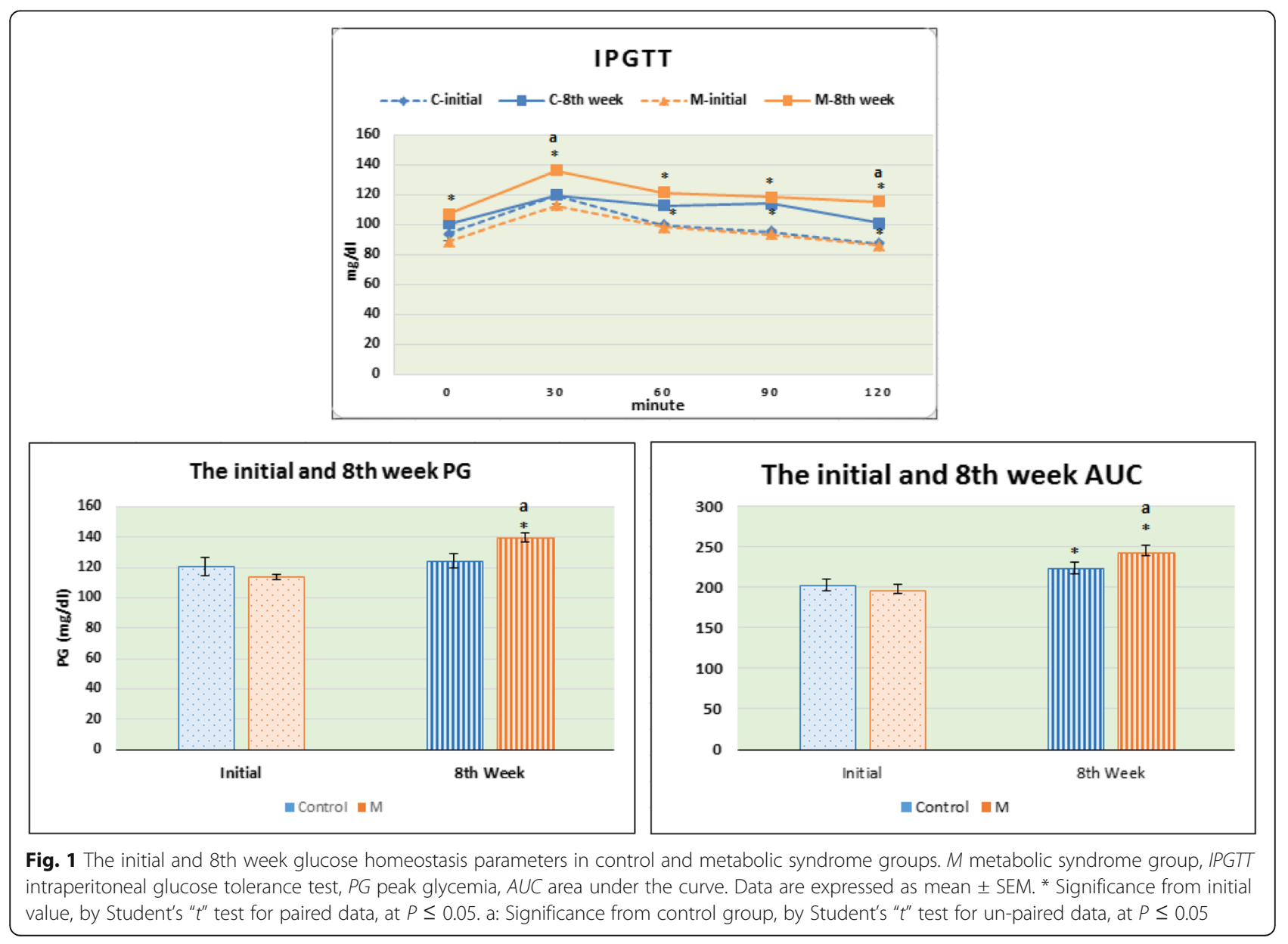



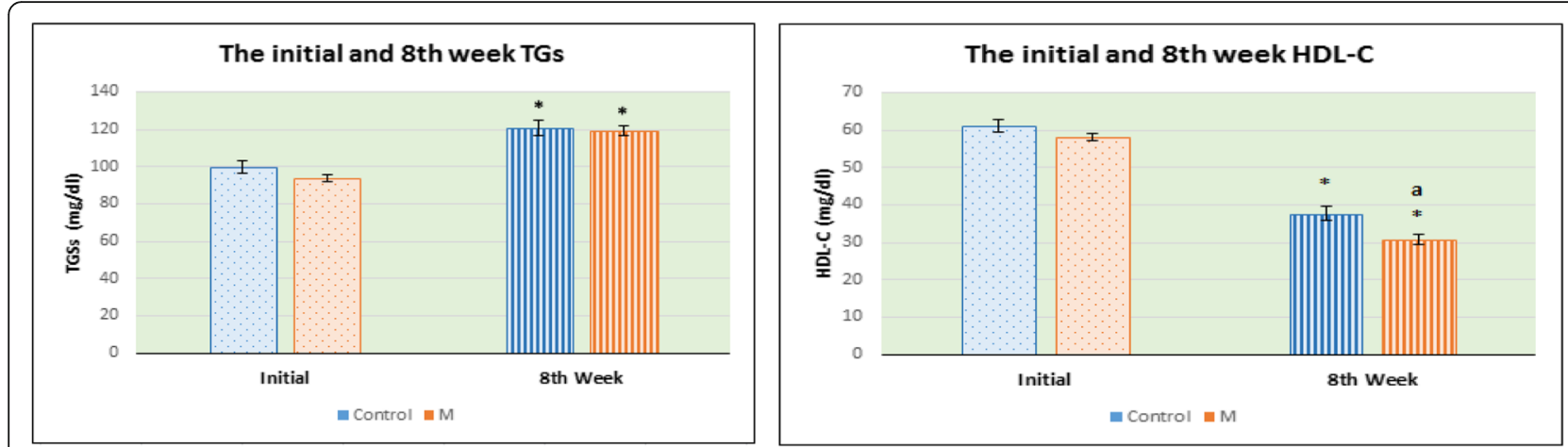

Fig. 2 The initial and $8^{\text {th }}$ week lipid parameters, in control and metabolic syndrome groups. M metabolic syndrome group, TGs triglycerides, HDL$C$ high density lipoprotein cholesterol. Data are expressed as mean \pm SEM. * Significance from initial value, by Student's " $t$ " test for paired data, at $P \leq 0.05$. a: Significance from control group, by Student's " $t$ " test for un-paired data, at $P \leq 0.05$

significantly decreased the final FBG only in MSF rats $(P$ $<0.05)$; reversion to regular rat chow, whether alone or in combination with alternate day fasting, resulted in a significant decrease in FBG and blood glucose levels at $30 \mathrm{~min}, 60 \mathrm{~min}, 90 \mathrm{~min}$, and $120 \mathrm{~min}$; PG; and AUC) in both MSRD $(P<0.05, P<0.001, P<0.005, P<0.001, P$ $<0.01, P<0.001, P<0.001$ respectively) and MSRDF $(P$ $<0.001, P<0.01, P<0.001, P<0.001, P<0.005, P<$ $0.005, P<0.001$ respectively) groups compared to their corresponding 8th week's values (Fig. 3).

Final results of $C, M S, M S R D, M S F$, and MSRDF $B W, B M I, W C, V F W$, and VFW/BW

MS group demonstrated non-significant changes in the final values of BW, BMI, WC, visceral fat weight (VFW), and VFW/BW compared to those of the C group; similarly, MSRD group had no significant difference in these parameters compared to MS and $\mathrm{C}$ rat groups. On the other hand, these parameters were significantly decreased in MSF group compared to MS group $(P<$ 0.001), MSRD group $(P<0.001, P<0.001, P<0.005, P$ $<0.001, P<0.001$ respectively) as well as $C$ group $(P<$ $0.001, P<0.005, P<0.005, P<0.001, P<0.001$ respectively), and as well as $C$ group $(P<0.001, P<0.005, P<$ $0.005, P<0.001, P<0.001$ respectively). Similarly, MSRDF group demonstrated significant decrease in all these parameters compared to MS $(P<0.001, P<0.005$, $P<0.001, P<0.001, P<0.001$ respectively $)$, MSRD $(P<$ $0.001)$ groups, as well as those of $C(P<0.001, P<0.05$, $P<0.001, P<0.001, P<0.001$ respectively) (Fig. 4).

Table 2 The 8th week and final anthropometric and lipid parameters in the five study groups

\begin{tabular}{|c|c|c|c|c|c|c|c|c|c|c|}
\hline & \multicolumn{2}{|l|}{ BW (gm) } & \multicolumn{2}{|c|}{$\mathrm{BMI}\left(\mathrm{gm} / \mathrm{cm}^{2}\right)$} & \multicolumn{2}{|l|}{$W C(\mathrm{~cm})$} & \multicolumn{2}{|c|}{ TGs (mg/dl) } & \multicolumn{2}{|c|}{$\mathrm{HDL}-\mathrm{C}(\mathrm{mg} / \mathrm{dl})$} \\
\hline & $8^{\text {th }}$ week & Final & $\begin{array}{l}8^{\text {th }} \\
\text { week }\end{array}$ & Final & $8^{\text {th }}$ week & Final & $8^{\text {th }}$ week & Final & $\begin{array}{l}8^{\text {th }} \\
\text { week }\end{array}$ & Final \\
\hline$C$ & $\begin{array}{l}186.80 \\
\pm 7.93 \\
(10)\end{array}$ & $\begin{array}{l}197.20 \\
\pm 8.06 \\
(10)\end{array}$ & $\begin{array}{l}0.48 \\
\pm 0.01 \\
(10)\end{array}$ & $\begin{array}{l}0.47 \\
\pm 0.01 \\
(10)\end{array}$ & $\begin{array}{l}11.90 \\
\pm 0.19 \\
(10)\end{array}$ & $\begin{array}{l}12.90^{*} \\
\pm 0.41 \\
(10)\end{array}$ & $\begin{array}{l}122.22 \\
\pm 3.35 \\
(9)\end{array}$ & $\begin{array}{l}83.11^{*} \\
\pm 3.93 \\
(9)\end{array}$ & $\begin{array}{l}38.38 \\
\pm 2.40 \\
(8)\end{array}$ & $\begin{array}{l}57.88^{*} \\
\pm 1.66 \\
(8)\end{array}$ \\
\hline MS & $\begin{array}{l}183.50 \\
\pm 5.97 \\
(14)\end{array}$ & $\begin{array}{l}194.50 \\
\pm 7.77 \\
(14)\end{array}$ & $\begin{array}{l}0.49 \\
\pm 0.02 \\
(14)\end{array}$ & $\begin{array}{l}0.48 \\
\pm 0.02 \\
(14)\end{array}$ & $\begin{array}{l}11.96 \\
\pm 0.18 \\
(14)\end{array}$ & $\begin{array}{l}12.93^{*} \\
\pm 0.30 \\
(14)\end{array}$ & $\begin{array}{l}116.10 \\
\pm 8.28 \\
(10)\end{array}$ & $\begin{array}{l}136.30^{*} \\
\pm 4.70 \\
(10)\end{array}$ & $\begin{array}{l}27.50 \\
\pm 3.69 \\
(10)\end{array}$ & $\begin{array}{l}27.40 \\
\pm 1.55 \\
(10)\end{array}$ \\
\hline MSRD & $\begin{array}{l}181.58 \\
\pm 7.20 \\
(12)\end{array}$ & $\begin{array}{l}198.00^{*} \\
\pm 8.26 \\
(12)\end{array}$ & $\begin{array}{l}0.48 \\
\pm 0.01 \\
(12)\end{array}$ & $\begin{array}{l}0.49 \\
\pm 0.01 \\
(12)\end{array}$ & $\begin{array}{l}12.17 \\
\pm 0.14 \\
(12)\end{array}$ & $\begin{array}{l}12.88^{*} \\
\pm 0.26 \\
(12)\end{array}$ & $\begin{array}{l}118.67 \\
\pm 6.53 \\
(9)\end{array}$ & $\begin{array}{l}107.56 \\
\pm 3.22 \\
(9)\end{array}$ & $\begin{array}{l}34.78 \\
\pm 2.74 \\
(9)\end{array}$ & $\begin{array}{l}45.11^{*} \\
\pm 1.62 \\
(9)\end{array}$ \\
\hline MSF & $\begin{array}{l}176.85 \\
\pm 4.65 \\
(13)\end{array}$ & $\begin{array}{l}151.31 \text { * } \\
\pm 5.59 \\
(13)\end{array}$ & $\begin{array}{l}0.48 \\
\pm 0.01 \\
(13)\end{array}$ & $\begin{array}{l}0.41^{*} \\
\pm 0.01 \\
(13)\end{array}$ & $\begin{array}{l}12.35 \\
\pm 0.17 \\
(13)\end{array}$ & $\begin{array}{l}11.46^{*} \\
\pm 0.23 \\
(13)\end{array}$ & $\begin{array}{l}121.11 \\
\pm 4.43 \\
(9)\end{array}$ & $\begin{array}{l}103.22^{*} \\
\pm 3.67 \\
(9)\end{array}$ & $\begin{array}{l}31.22 \\
\pm 2.68 \\
(9)\end{array}$ & $\begin{array}{l}48.22^{*} \\
\pm 2.60 \\
(9)\end{array}$ \\
\hline MSRDF & $\begin{array}{l}172.08 \\
\pm 7.18 \\
(12)\end{array}$ & $\begin{array}{l}148.92^{*} \\
\pm 5.85 \\
(12)\end{array}$ & $\begin{array}{l}0.50 \\
\pm 0.02 \\
(12)\end{array}$ & $\begin{array}{l}0.42^{*} \\
\pm 0.01 \\
(12)\end{array}$ & $\begin{array}{l}12.54 \\
\pm 0.21 \\
(12)\end{array}$ & $\begin{array}{l}11.17^{*} \\
\pm 0.20 \\
(12)\end{array}$ & $\begin{array}{l}114.75 \\
\pm 7.32 \\
(8)\end{array}$ & $\begin{array}{l}96.25 \\
\pm 3.24 \\
(8)\end{array}$ & $\begin{array}{l}31.00 \\
\pm 2.90 \\
(8)\end{array}$ & $\begin{array}{l}50.25^{*} \\
\pm 2.46 \\
(8)\end{array}$ \\
\hline
\end{tabular}

C, control group, MS, untreated metabolic syndrome group, MSRD, metabolic syndrome group reverted to regular rat chow, MSF, metabolic syndrome group on alternate day fasting, MSRDF, metabolic syndrome group reverted to regular rat chow and on alternate day fasting;

BW, body weight; BMI, body mass index; WC, waist circumference; TGs, triglycerides; HDL-C, high density lipoprotein cholesterol

In the parenthesis is the number of observations

Data are expressed as mean \pm SEM

*: Significance from $8^{\text {th }}$ week value, by Student's " $t$ " test for paired data, at $\mathrm{P} \leq 0.05$ 


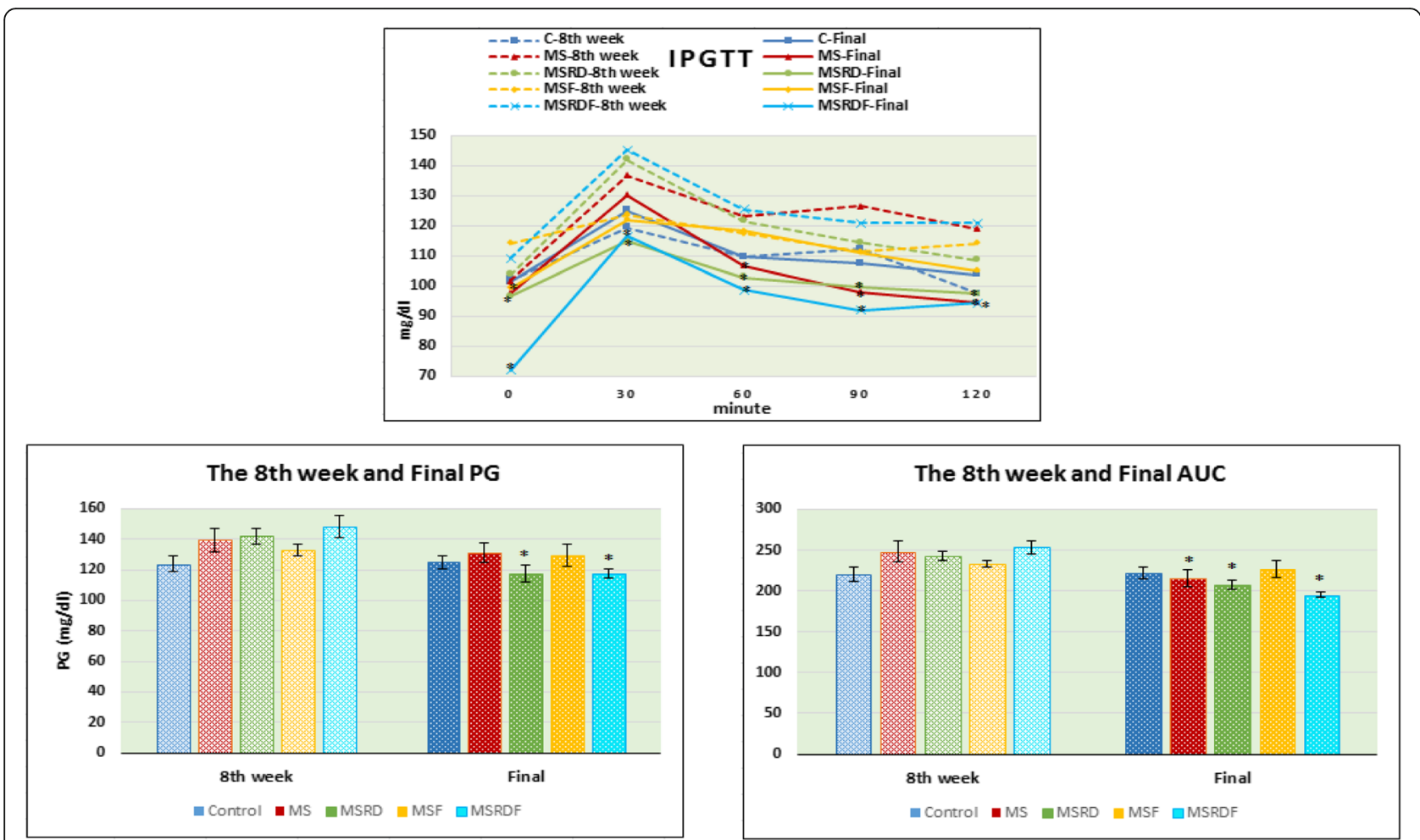

Fig. 3 The 8th week and final glucose homeostasis parameters in the five study groups. MS untreated metabolic syndrome group, MSRD metabolic syndrome group reverted to regular rat chow, MSF metabolic syndrome group on alternate day fasting, MSRDF metabolic syndrome group reverted to regular rat chow and on alternate day fasting, IPGT intraperitoneal glucose tolerance test, $P G$ peak glycemia, AUC area under the curve. Data are expressed as mean \pm SEM. * Significance from 8th week value, by Student's " $t$ " test for paired data, at $P \leq 0.05$

\section{FBG, IPGTT, PG, AUC, HbA1C, serum fasting insulin, and HOMA-IR}

Final values of FBG and blood glucose during IPGTT; PG; and AUC; $\mathrm{Hb}$ A1C, all were insignificantly changed in MS group compared to those of the $\mathrm{C}$ rats, while the serum fasting insulin level and HOMA-IR were significantly increased in MS group compared to the $\mathrm{C}$ group $(P<0.001)$. MSRD group showed non-significant changes in the final values of FBG and blood glucose during IPGTT, PG, and AUC in addition to $\mathrm{Hb} A 1 \mathrm{C}$ when compared to those of the MS or C groups. MSRD group showed significant decrease in serum fasting insulin level and HOMA-IR compared to MS group $(P<$ $0.001, P<0.005$ respectively), and significant increase compared to the $\mathrm{C}$ group $(P<0.001)$. MSF group showed significant increase in the levels of blood glucose during IPGTT at $90 \mathrm{~min}, 120 \mathrm{~min}(P<0.05)$, nonsignificant change in PG and AUC but significant decrease in serum fasting insulin level, HOMA-IR, and $\mathrm{Hb}$ A1C compared to MS rats $(P<0.005, P<0.001, P<$ 0.005 respectively). Compared to MSRD group, MSF group presented a significantly elevated blood glucose levels during IPGTT at $60 \mathrm{~min}$ and $90 \mathrm{~min}(P<0.05)$, along with non-significant changes in PG, AUC, serum fasting insulin level, HOMA-IR, and $\mathrm{Hb}$ A1C. In comparison to the $\mathrm{C}$ group, all the measured glucose homeostasis parameters were not significantly different in MSF rats except for a significantly higher serum fasting insulin and HOMA-IR $(P<0.001)$. MSRDF group exhibited a significant lower level of fasting blood glucose when compared to MSRD, MSF, C, and MS rat groups $(P<0.005)$. The blood glucose levels during IPGTT at $60 \mathrm{~min}, 90 \mathrm{~min}$, and $120 \mathrm{~min}$ were decreased in MSRDF group compared with MSF group $(P<0.01$, $P<0.005, P<0.05$ respectively). Compared to the $\mathrm{C}$ group, the levels of blood glucose measured during IPGTT in MSRDF group were not significantly different except for a significantly lower value at $90 \mathrm{~min}(P<$ $0.05)$. PG was not significantly changed in MSRDF group compared to the other four groups. AUC was significantly decreased in MSRDF group in comparison to MSF and control groups $(P<0.01, P<0.05$ respectively). Serum fasting insulin and HOMA-IR were significantly decreased in MSRDF group versus MS $(P<0.001)$, MSRD $(P<0.05, P<0.005$ respectively), and MSF $(P<$ $0.005, P<0.01$ respectively) groups. HbA1C was decreased in MSRDF group compared with MSRD, MSF, and MS, groups, being significant in MS group only $(P<$ $0.01)$. In comparison to $C$ rats, serum fasting insulin was still significantly higher in MSRDF group $(P<0.005)$, 


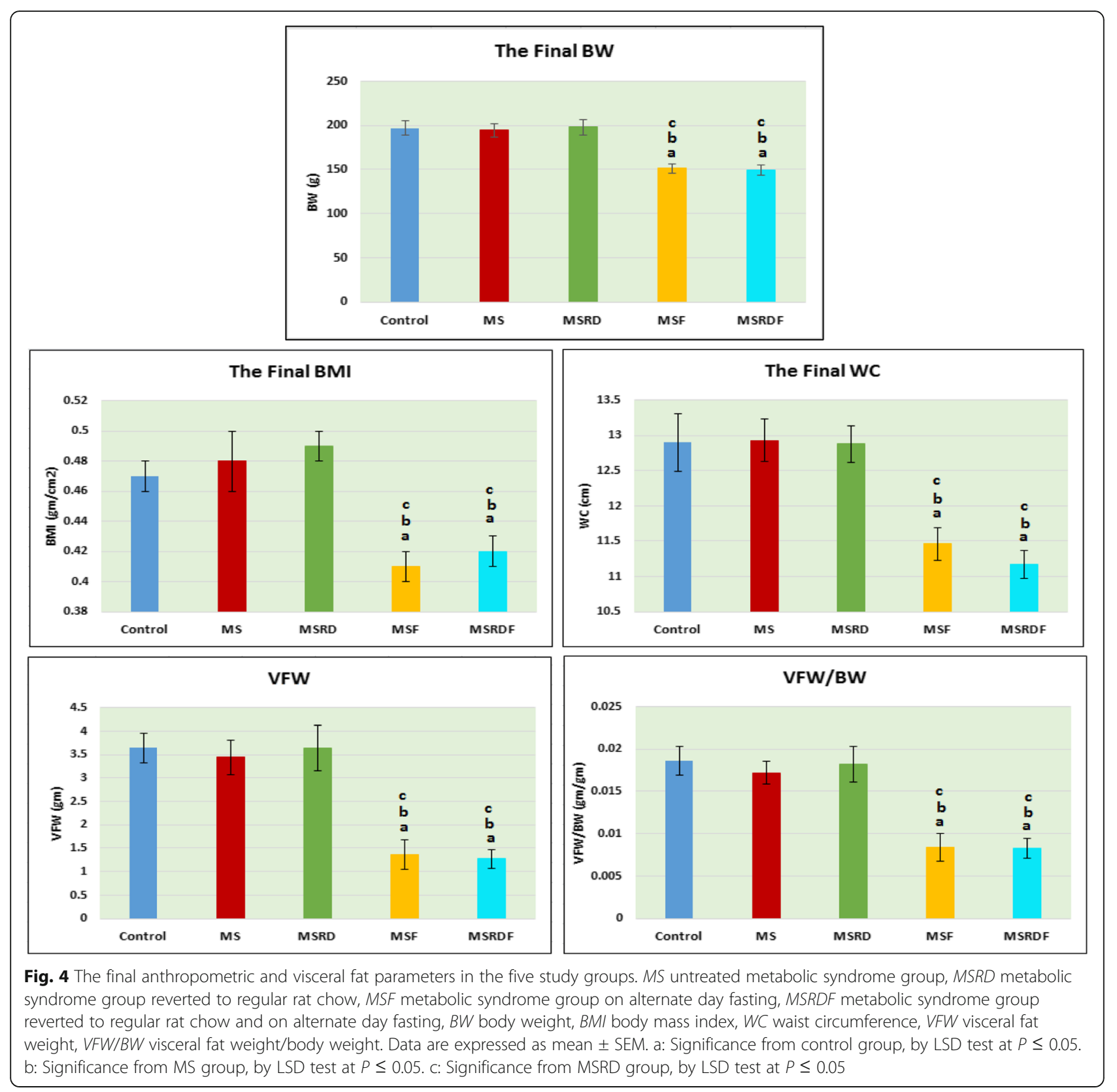

while HOMA-IR and HbA1C were not significantly different (Fig. 5 and Table 3).

\section{Lipid profile}

MS group showed a significantly higher final serum levels of TGs, TC, and LDL-C associated with a significantly lower HDL-C compared to the $\mathrm{C}$ group $(P<$ 0.001). MSRD group demonstrated a significantly reduced final serum levels of TGs, TC, and LDL-C $(P<$ 0.001, $P<0.005, P<0.001$ respectively) associated with a significantly elevated HDL-C $(P<0.001)$ compared to the MS group; however, TGs, TC, and LDL-C were still significantly higher $(P<0.001, P<0.005, P<0.001$ respectively), and HDL-C was significantly lower $(P<$ 0.001) compared to the $C$ group. Similarly, MSF group demonstrated a significantly decreased TGs, TC, and LDL-C associated with a significantly elevated HDL-C compared to the MS group $(P<0.001)$; however, TGs, $\mathrm{TC}$, and LDL-C were still significantly higher $(P<0.005$, $P<0.05, P<0.05$ respectively), and HDL-C was significantly lower $(P<0.005)$ compared to the $C$ group. On comparing the parameters of lipid profile between the MSRD and MSF groups, non-significant changes were observed. MSRDF group exhibited a significant decrease of the final serum levels of TGs, TC, and LDL-C, along with a rise in HDL-C compared to the MS group $(P<$ 


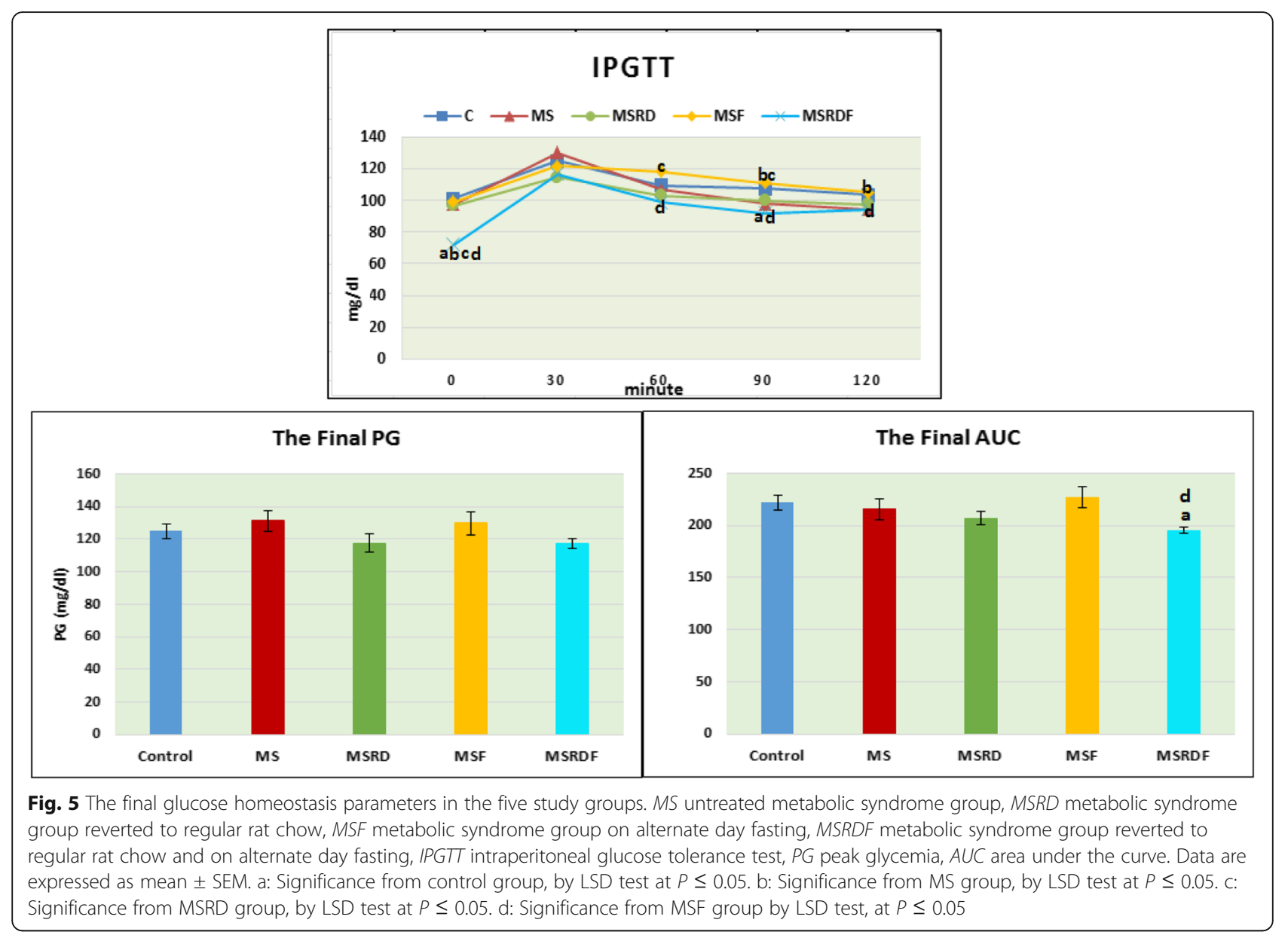

0.001) as well as MSRD groups as regards serum levels of TGs, TC, and LDL $(P<0.05, P<0.005$, and $P<$ 0.005 , respectively) with insignificant change in HDL-C. Furthermore, in comparison to the MSF group, MSRDF group showed a significant decrease in the final serum

Table 3 The final glucose homeostasis parameters in the five study groups

\begin{tabular}{llll}
\hline & Insulin $(\mathrm{ng} / \mathrm{ml})$ & HOMA-IR & HbA1C (mg/dl) \\
\hline $\mathrm{C}$ & $0.13 \pm 0.01(9)$ & $1.09 \pm 0.10(9)$ & $5.97 \pm 0.30(10)$ \\
MS & $0.91 \pm 0.06^{\mathrm{a}}(10)$ & $7.35 \pm 0.83^{\mathrm{a}}(10)$ & $6.60 \pm 0.39(14)$ \\
MSRD & $0.61 \pm 0.07^{\mathrm{a}, \mathrm{b}}(9)$ & $4.67 \pm 0.55^{\mathrm{a}, \mathrm{b}}(9)$ & $6.08 \pm 0.52(12)$ \\
MSF & $0.64 \pm 0.07^{\mathrm{a}, \mathrm{b}}(9)$ & $4.46 \pm 0.52^{\mathrm{a}, \mathrm{b}}(9)$ & $5.25 \pm 0.11^{\mathrm{b}}(13)$ \\
MSRDF & $0.39 \pm 0.05^{\mathrm{a}, \mathrm{b}, \mathrm{c}, \mathrm{d}}(9)$ & $2.29 \pm 0.35^{\mathrm{b}, \mathrm{c}, \mathrm{d}}(9)$ & $5.23 \pm 0.16^{\mathrm{b}}(12)$
\end{tabular}

C, control group, MS, untreated metabolic syndrome group, MSRD, metabolic syndrome group reverted to regular rat chow, MSF, metabolic syndrome group on alternate day fasting, MSRDF, metabolic syndrome group reverted to regular rat chow and on alternate day fasting; HOMA-IR, homeostasis model assessment of insulin resistance; $\mathrm{HbA} 1 \mathrm{C}$, glycosylated hemoglobin Data are expressed as mean \pm SEM

In the parenthesis is the number of observations

a: Significance from control group, by LSD test at $P \leq 0.05$

b: Significance from MS group, by LSD test at $P \leq 0.05$

c: Significance from MSRD group, by LSD test at $P \leq 0.05$

$\mathrm{d}$ : Significance from MSF group, by LSD test at $P \leq 0.05$ levels TC and LDL-C $(P<0.05)$ with no significant changes in TGs or HDL-C. Moreover, the final serum levels of TC and LDL-C in MSRDF group attained those of the controls, yet TGs was still significantly higher $(P<$ $0.05)$ and the HDL-C was significantly lower $(P<0.005)$ than those of the $C$ group (Table 4).

\section{LW, LW/BW, ALT, albumin, bilirubin, MDA, and CRP}

MS group showed a significant increase in the final liver weight (LW) and liver weight/body weight ratio (LW/ BW) versus the $C$ group $(P<0.001)$. MSRD and MSF groups presented a significant decrease in LW and LW/ BW compared to MS group $(P<0.001)$. Also, LW was significantly decreased in MSF group versus MSRD group $(P<0.05)$, while the LW/BW was not significantly changed. In comparison to the control rats, $\mathrm{LW} / \mathrm{BW}$ was still significantly higher in MSRD and in MSF groups $(P$ $<0.05, P<0.001$ respectively), but the LW was not significantly different. MRSDF group showed a decrease in LW $(P<0.001, P<0.001, P<0.05$, respectively) compared to MS, MSRD, and MSF groups as well as LW/ BW when compared to the MS and MSF groups only ( $P$ $<0.001$ ) with the LW in MSRDF group becoming 
Table 4 The final lipid profile parameters in the five study groups

\begin{tabular}{lllll}
\hline & TGs $(\mathrm{mg} / \mathrm{dl})$ & TC $(\mathrm{mg} / \mathrm{dl})$ & LDL-C $(\mathrm{mg} / \mathrm{dl})$ & HDL-C $(\mathrm{mg} / \mathrm{dl})$ \\
\hline $\mathrm{C}(9)$ & $83.11 \pm 3.93$ & $144.22 \pm 4.25$ & $69.16 \pm 5.09$ & $58.44 \pm 1.57$ \\
MS (10) & $136.30 \pm 4.70^{\mathrm{a}}$ & $213.00 \pm 9.18^{\mathrm{a}}$ & $158.34 \pm 10.20^{\mathrm{a}}$ & $27.40 \pm 1.55^{\mathrm{a}}$ \\
MSRD (9) $^{\text {MSF(9) }}$ & $107.56 \pm 3.22^{\mathrm{a}, \mathrm{b}}$ & $176.33 \pm 5.63^{\mathrm{a}, \mathrm{b}}$ & $109.71 \pm 4.96^{\mathrm{a}, \mathrm{b}}$ & $45.11 \pm 1.62^{\mathrm{a}, \mathrm{b}}$ \\
MSRDF (9) & $103.22 \pm 3.67^{\mathrm{a}, \mathrm{b}}$ & $165.67 \pm 7.56^{\mathrm{a}, \mathrm{b}}$ & $96.80 \pm 8.65^{\mathrm{a}, \mathrm{b}}$ & $48.22 \pm 2.60^{\mathrm{a}, \mathrm{b}}$ \\
\hline
\end{tabular}

C, control group, MS, untreated metabolic syndrome group, MSRD, metabolic syndrome group reverted to regular rat chow, MSF, metabolic syndrome group on alternate day fasting, MSRDF, metabolic syndrome group reverted to regular rat chow and on alternate day fasting; TGs, triglycerides; TC, total cholesterol; LDL-C, low-density lipoprotein cholesterol; HDL-C, high-density lipoprotein cholesterol

Data are expressed as mean \pm SEM

In the parenthesis is the number of observations

a. Significance from control group, by LSD test at $\mathrm{P} \leq 0.05$

b: Significance from MS group, by LSD test at $P \leq 0.05$

c: Significance from MSRD group, by LSD test at $P \leq 0.05$

$\mathrm{d}$ : Significance from MSF group, by LSD test at $\mathrm{P} \leq 0.05$

significantly lower than that of the control rats $(P<$ 0.05 ) and with the LW/BW insignificantly different from control value. MS group demonstrated a significant increase in the serum level of ALT associated with a significantly lower level of serum albumin compared to the $\mathrm{C}$ group $(P<0.001)$. Although the levels of serum ALT were significantly decreased associated with a significant increase in serum albumin in MSRD and MSF groups compared to the MS group $(P<0.001)$, yet these parameters were not normalized when compared to control rats. In comparison to the MSRD group, serum level of albumin was not significantly changed in MSF group, but the serum level of ALT was significantly lower $(P<$ 0.05). MSRDF rats showed significant decrease of ALT $(P<0.001)$ and non-significant changes of albumin compared to MSRD group, but when compared to MSF group, no significant difference was observed in either ALT or albumin. However, MSRDF group showed a significant decrease in serum ALT together with a significant increase in serum albumin compared to MS group $(P<0.001)$. In comparison to the $C$ group, the serum ALT was not significant, while the serum albumin was significantly lower $(P<0.05)$ in MSRDF group. Concerning the serum bilirubin levels, non-significant changes were recorded among the five study groups (Table 5).

MDA was significantly increased in MS group versus $C$ group $(P<0.001)$, and was significantly decreased in MSRD, MSF, and MSRDF groups in comparison to MS group $(P<0.001)$, though it was still significantly higher than those of the control rats in these three groups $(P<$ $0.001, P<0.01, P<0.05$ respectively). MSF and MSRDF presented significantly lower liver levels of MDA in comparison to the MSRD rats $(P<0.05, P<0.01$ respectively). The liver levels of MDA were comparable in MSF and MSRDF groups. Serum level of CRP was

Table 5 The final liver parameters and serum C-reactive protein (CRP) in the five study groups

\begin{tabular}{|c|c|c|c|c|c|c|c|}
\hline & $\begin{array}{l}\text { LW } \\
\text { (gm) }\end{array}$ & LW/BW (gm/gm) & $\begin{array}{l}\text { ALT } \\
\text { (U/L) }\end{array}$ & Albumin (gm/ml) & Bilirubin (mg/dl) & $\begin{array}{l}\text { MDA } \\
(\mathrm{nmol} / \mathrm{gm})\end{array}$ & $\begin{array}{l}\text { CRP } \\
\text { (ng/ml) }\end{array}$ \\
\hline C & $\begin{array}{l}5.35 \pm 0.27 \\
(10)\end{array}$ & $\begin{array}{l}0.0272 \\
\pm 0.00096(10)\end{array}$ & $\begin{array}{l}29.56 \pm 1.74 \\
(9)\end{array}$ & $\begin{array}{l}5.19 \pm 0.13 \\
(9)\end{array}$ & $\begin{array}{l}0.54 \pm 0.09 \\
(9)\end{array}$ & $\begin{array}{l}38.23 \pm 2.83 \\
(9)\end{array}$ & $\begin{array}{l}0.28 \pm 0.05 \\
(9)\end{array}$ \\
\hline MS & $\begin{array}{l}8.13 \pm 0.38^{a} \\
(14)\end{array}$ & $\begin{array}{l}0.0419 \pm \\
0.00151^{\mathrm{a}}(14)\end{array}$ & $\begin{array}{l}81.20 \pm 1.33^{a} \\
(10)\end{array}$ & $\begin{array}{l}3.68 \pm 0.14^{a} \\
(10)\end{array}$ & $\begin{array}{l}0.55 \pm 0.09 \\
(10)\end{array}$ & $\begin{array}{l}129.07 \pm 4.29^{a} \\
(10)\end{array}$ & $\begin{array}{l}1.20 \pm 0.11^{\mathrm{a}} \\
(10)\end{array}$ \\
\hline MSRD & $\begin{array}{l}6.21 \pm 0.31^{b} \\
(12)\end{array}$ & $\begin{array}{l}0.0313 \pm \\
0.00109^{\mathrm{a}, \mathrm{b}}(12)\end{array}$ & $\begin{array}{l}44.00 \pm 1.56^{\mathrm{a}, \mathrm{b}} \\
\text { (9) }\end{array}$ & $\begin{array}{l}4.45 \pm 0.12^{\mathrm{a}, \mathrm{b}} \\
(9)\end{array}$ & $\begin{array}{l}0.48 \pm 0.06 \\
(9)\end{array}$ & $\begin{array}{l}68.90 \pm 5.73^{a, b} \\
\text { (9) }\end{array}$ & $\begin{array}{l}0.50 \pm 0.07^{b} \\
(9)\end{array}$ \\
\hline MSF & $\begin{array}{l}5.21 \pm 0.19^{b, c} \\
(13)\end{array}$ & $\begin{array}{l}0.0345 \pm \\
0.00063^{a, b}(13)\end{array}$ & $\begin{array}{l}38.22 \pm 1.78^{a, b, c} \\
(9)\end{array}$ & $\begin{array}{l}4.51 \pm 0.14^{\mathrm{a}, \mathrm{b}} \\
(9)\end{array}$ & $\begin{array}{l}0.49 \pm 0.07 \\
(9)\end{array}$ & $\begin{array}{l}55.99 \pm 4.79^{\mathrm{a}, \mathrm{b}, \mathrm{c}} \\
(9)\end{array}$ & $\begin{array}{l}0.40 \pm 0.07^{b} \\
(9)\end{array}$ \\
\hline MSRDF & $\begin{array}{l}4.25 \pm 0.31^{a, b, c, d} \\
(12)\end{array}$ & $\begin{array}{l}0.0283 \pm \\
0.00141^{\mathrm{b}, \mathrm{d}}(12)\end{array}$ & $\begin{array}{l}33.67 \pm 1.77^{b, c} \\
(9)\end{array}$ & $\begin{array}{l}4.77 \pm 0.17^{a, b} \\
(9)\end{array}$ & $\begin{array}{l}0.47 \pm 0.06 \\
(9)\end{array}$ & $\begin{array}{l}51.14 \pm 3.61^{a, b, c} \\
(9)\end{array}$ & $\begin{array}{l}0.33 \pm 0.05^{\mathrm{b}} \\
(9)\end{array}$ \\
\hline
\end{tabular}

C, control group, MS, untreated metabolic syndrome group, MSRD, metabolic syndrome group reverted to regular rat chow, MSF, metabolic syndrome group on alternate day fasting, MSRDF, metabolic syndrome group reverted to regular rat chow and on alternate day fasting; LW, liver weight; LW/BW, liver weight/body weight; ALT , serum alanine transferase; MDA, malondialdehyde content of liver tissue

Data are expressed as mean \pm SEM

In the parenthesis is the number of observations

a: Significance from control group, by LSD test at $P \leq 0.05$

b: Significance from MS group, by LSD test at $P \leq 0.05$

c: Significance from MSRD group, by LSD test at $P \leq 0.05$

$\mathrm{d}$ : Significance from MSF group, by LSD test at $P \leq 0.05$ 
significantly increased in MS group versus $C$ group $(P<$ 0.001). MSRD, MSF, and MSRDF groups showed a significant decrease in serum CRP compared to MS group $(P<0.001)$, becoming not significantly different from the level of control rats. The serum level of CRP was not significantly different among MSRD, MSF, and MSRDF groups (Table 5).

\section{Results of correlation study}

Serum alanine transferase (ALT) showed significant +ve correlations with VFW, LW, HOMA-IR serum TGs, and LDL-C and significant -ve correlations with serum HDL-C. Serum albumin showed significant -ve correlations with LW. Liver oxidative stress marker [malondialdehyde content of liver tissue (MDA)] showed significant +ve correlations with HOMA-IR and LDL-C and significant -ve correlations with serum HDL-C (Table 6).

\section{Histopathological study}

Histopathological examination of livers of the C group stained with $\mathrm{H}$ and $\mathrm{E}$ stain after 8 weeks, showed branching and anastomosing cords of hepatocytes radiating from the central vein (cv). Livers of the $M$ group showed highly vacuolated hepatocytes at the periphery of the classic hepatic lobule [zone 1] [*]. Mild cellular infiltration is seen (Figs. 6 and 7).

Histopathological examination of livers of the C group stained with $\mathrm{H}$ and $\mathrm{E}$ stain after 12 weeks showed branching and anastomosing cords of hepatocytes radiating from the central vein (cv). Livers of the MS group showed highly vacuolated hepatocytes at the periphery of the classic hepatic lobule [zone 1]. Livers of the MSRD group showed an apparent moderate decrease in the vacuolated hepatocytes. Livers of the MSF group showed an apparent decrease in the vacuolated hepatocytes. Liver of the MSRDF group showed absence of vacuolated hepatocytes (Fig. 8).

Histopathological examination of livers of the $\mathrm{C}$ group stained with periodic acid-Schiff (PAS) stain after 12 weeks showed PAS +ve glycogen granules almost in all hepatocytes. Livers of the MS group showed PAS +ve glycogen granules at the hepatocytes around central vein [zone 3]; vacuolated hepatocytes at the periphery of classic hepatic lobule have no PAS +ve granules. Livers of the MSRD group showed PAS + ve glycogen granules in vacuolated hepatocytes at the periphery of classic hepatic lobule [zone 1], the hepatocytes around central vein have no PAS +ve granules. Livers of the MSF and MSRDF groups did not show PAS + ve glycogen granules (Fig. 9).

Histopathological examination of livers of the $\mathrm{C}$ group stained with Maison Trichome stain (MTS) after 12 weeks showed collagen fibers around central vein and in portal area; minimal amount of collagen is seen in between hepatocytes cords. Livers of the MS, MSRD, MSF, and MSRDF groups showed collagen fibers almost comparable to the control group (Fig. 10).

\section{Diagnosis and grading of NAFLD}

At the end of 8th week, $\mathrm{C}$ group showed $0 \%$ steatosis, FC score (1); and M group 69\% steatosis, FC score (4).

Four weeks later at the end of the study, C and MSRD F groups showed 0\% steatosis, FC score (1); MS group $82 \%$ steatosis, FC score (4); and MSRD and MSF groups $42 \%$ steatosis, FC score (3).

At the end of 8th week, $M$ group was classified as grade (1) (PF: 0 and AS: 2). Four weeks later at the end of the study, MS, MSRD, and MSF groups were classified as grade (1), MS (PF: 0 and AS: 4), MSRD (PF: 0 and AS: 3), and MSF (PF: 0 and AS: 1) (Table 7).

Table 6 Correlation studies

\begin{tabular}{|c|c|c|c|c|c|c|c|}
\hline & & VFW & LW & HOMA-IR & TGs & HDL-C & LDL-C \\
\hline \multirow[t]{2}{*}{ ALT } & $r$ & $\begin{array}{l}0.419 * * \\
(n=46)\end{array}$ & $\begin{array}{l}0.759 * * \\
(n=46)\end{array}$ & $\begin{array}{l}0.687^{* *} \\
(n=46)\end{array}$ & $\begin{array}{l}0.818^{* *} \\
(n=46)\end{array}$ & $\begin{array}{c}-0.840^{* *} \\
(n=46)\end{array}$ & $\begin{array}{l}0.790^{* *} \\
(\mathrm{n}=46)\end{array}$ \\
\hline & P & $<0.005$ & $<0.001$ & $<0.001$ & $<0.001$ & $<0.001$ & $<0.001$ \\
\hline \multirow[t]{2}{*}{ Albumin } & r & $\begin{array}{l}-0.054 \\
(n=46)\end{array}$ & $\begin{array}{l}-0.521^{* *} \\
(n=46)\end{array}$ & $\begin{array}{l}-0.625^{* *} \\
(n=46)\end{array}$ & $\begin{array}{l}-0.765^{* *} \\
(n=46)\end{array}$ & $\begin{array}{l}0.655^{* *} \\
(n=46)\end{array}$ & $\begin{array}{l}-0.655^{* *} \\
(\mathrm{n}=46)\end{array}$ \\
\hline & $P$ & NS & $<0.001$ & $<0.001$ & $<0.001$ & $<0.001$ & $<0.001$ \\
\hline \multirow[t]{2}{*}{ MDA } & $r$ & $\begin{array}{l}0.311^{*} \\
(n=46)\end{array}$ & $\begin{array}{c}0.744^{* *} \\
(n=46)\end{array}$ & $\begin{array}{c}0.690^{* *} \\
(n=46)\end{array}$ & $\begin{array}{l}0.853^{* *} \\
(n=46)\end{array}$ & $\begin{array}{c}-0.893^{* *} \\
(n=46)\end{array}$ & $\begin{array}{c}0.809 * * \\
(n=46)\end{array}$ \\
\hline & $P$ & $<0.05$ & $<0.001$ & $<0.001$ & $<0.001$ & $<0.001$ & $<0.001$ \\
\hline
\end{tabular}

ALT , serum alanine transferase; MDA, malondialdehyde content of liver tissue; VFW, Visceral Fat Weight; LW, liver weight;HOMA-IR, homeostasis model assessment of insulin resistance; TGs, triglycerides; LDL-C, low-density lipoprotein cholesterol; HDL-C, high-density lipoprotein cholesterol r: Correlation coefficient

In the parenthesis is the number of observations

**. Correlation is significant at the 0.01 level (2-tailed)

*. Correlation is significant at the 0.05 level (2-tailed) 

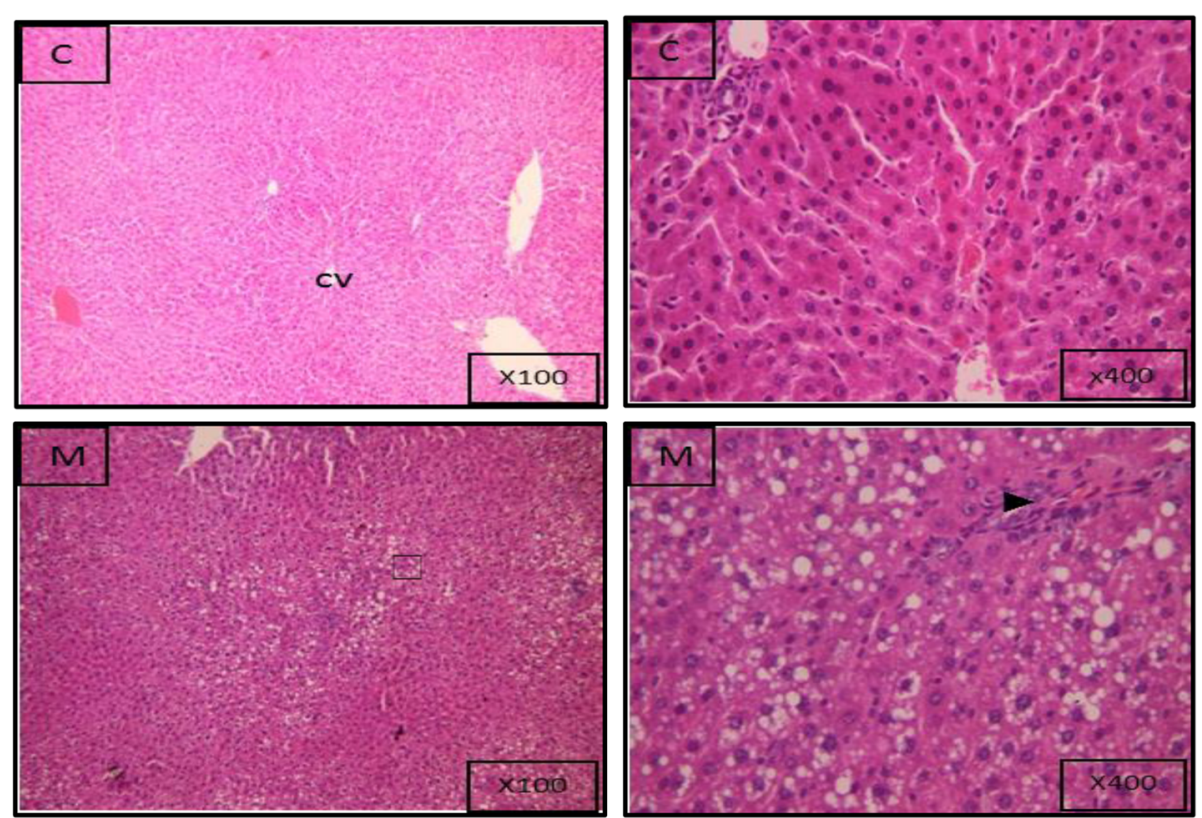

Fig. 6 Liver tissue photomicrograph of control (C) and metabolic syndrome (M) groups after 8 weeks (H\&E)

\section{Discussion}

Understanding the pathophysiology of MetS is essential, if therapy of MetS-associated NAFLD is to be considered. Pathophysiology of MetS is multifactorial with the unhealthy lifestyle a strongly predisposing factor [42]. Lifestyle aspects include nutrition, physical activity, sleeping hours, smoking, alcohol intake, working hours, hours of watching television, afternoon napping, and social life with friends [42].

Healthy nutrition as described by Mattson et al. [43] includes healthy diet (Mediterranean diet), intake of nutraceuticals, and dietary constriction in the form of caloric restriction or intermittent fasting-defined as periods of unrestricted feeding alternating with periods of caloric restriction.

Unhealthy nutrition is an aspect of unhealthy life style and includes intake of foods with high caloric content, high glycemic index, high content of fructose, high percentage of saturated to polyunsaturated fat, low fruit and vegetable fiber content, as well as irregular eating [44-47].

Garralda-Del-Villar et al. [42] hypothesized that higher adherence to the healthy lifestyle is associated with a lower risk of developing MetS. In the present work, MetS was induced by applying one aspect of unhealthy lifestyle namely unhealthy nutrition in the form of excess fructose intake both in food and drink which mimic the increasing intake of this sweetener in foods and drinks by humans [48]. Fructose content in diet and drink of MS group was equal to starch content in the control rat diet.

The present study was planned to investigate the ability of dietary intervention in the form of reversion to normal diet-with or without adoption of a healthy dietary pattern like zero-calorie intermittent fasting-to cure MetSassociated steatosis which is the hallmark of diagnosis of NAFLD.
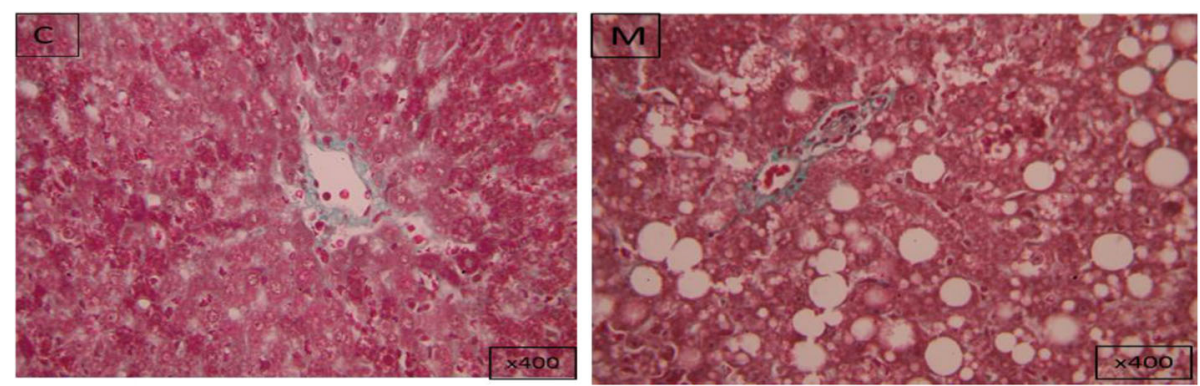

Fig. 7 Liver tissue photomicrograph of control (C) and metabolic syndrome (M) groups after 8 weeks (MT) 


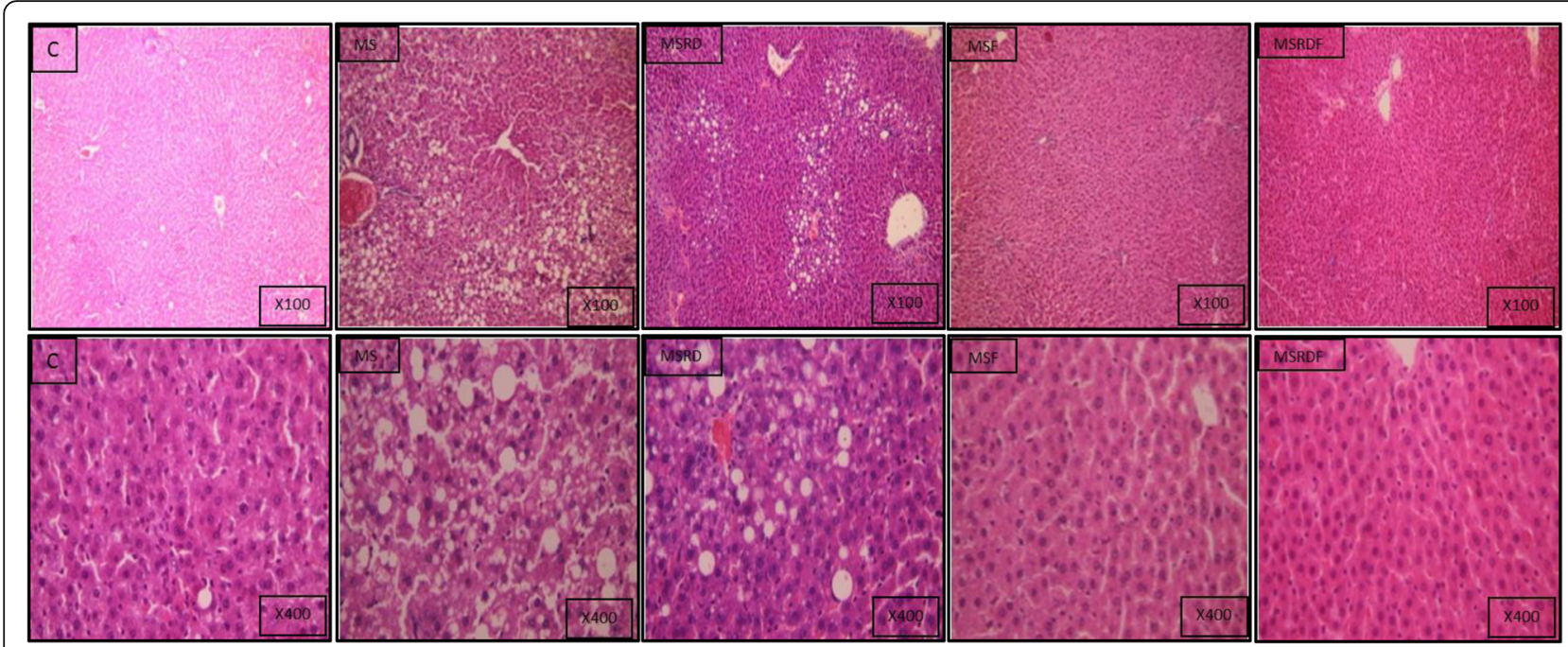

Fig. 8 Liver tissue photomicrograph of the five study groups after 12 weeks (H\&E). C control group, MS untreated metabolic syndrome group, MSRD metabolic syndrome group reverted to regular rat chow, MSF metabolic syndrome group on alternate day fasting, MSRDF metabolic syndrome group reverted to regular rat chow and on alternate day fasting

The results of the present study revealed that 8 weeks of high fructose diet (HFD) was able to induce features of MetS in $\mathrm{M}$ rats as evidenced by the significant increase in WC, PG, and AUC as well as the significant decrease of HDL-C compared to control rats. Additionally, in comparison to their initial values, $M$ group presented a significant increase in WC, FBS, PG, AUC, and TG associated with a significant decrease in HDL-C after 8 weeks of HFD.

According to the criteria of harmonizing definition of Alberti et al. [1], $M$ rats, in the present study, showed two criteria of MetS, namely high FBG and low HDL-C, skipping the normal cutoff values of FBG (>100 mg\%), and HDL-C $(<40 \mathrm{mg} / \mathrm{dl})$. Although the cutoff value of WC in the previous definition is not applicable to rats, yet the significant increase in WC in $\mathrm{M}$ compared to control rats could be considered the third criterion needed to diagnose MetS in this group. This was consistent with the study of Di Luccia et al. [49], on Sprague-Dawley rats which developed the same MetS criteria, developed in the present study, after 8 weeks of HFD.

Moreover, histopathological study of $\mathrm{M}$ rats' livers showed liver steatosis (score-4), hepatocyte ballooning (score-1), and lobular inflammation (score-1), making activity score- 2 which both indicate the development of grade-1 NAFLD according to the score of Mendler et al. [40], and highlighting the early emergence of steatohepatitis. Thus, the results of $M$ rats in the present study confirm the close association between unhealthy nutrition in the form of excess fructose intake, MetS, and steatohepatitis and agree with the findings of Mamikutty et al. [50].

At the end of the study, MS rats showed amelioration of two criteria of MetS (VFW, VFW/BW, and FBG) with HDL-C value remaining below the cutoff value of low HDL-C ( $<40 \mathrm{mg} / \mathrm{dl})$ according to Alberti et al. [1]. However, liver derangement was evident in the form of significantly increased LW, LW/BW, and serum ALT as well as decreased serum albumin compared to control
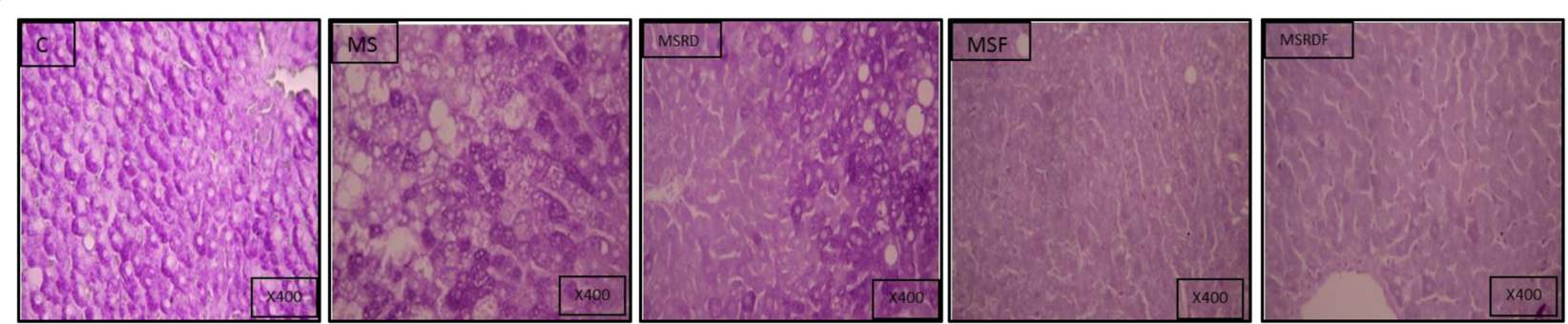

Fig. 9 Liver tissue photomicrograph of the five study groups after 12 weeks (PAS). C control group, MS untreated metabolic syndrome group, MSRD metabolic syndrome group reverted to regular rat chow, MSF metabolic syndrome group on alternate day fasting, MSRDF metabolic syndrome group reverted to regular rat chow and on alternate day fasting 


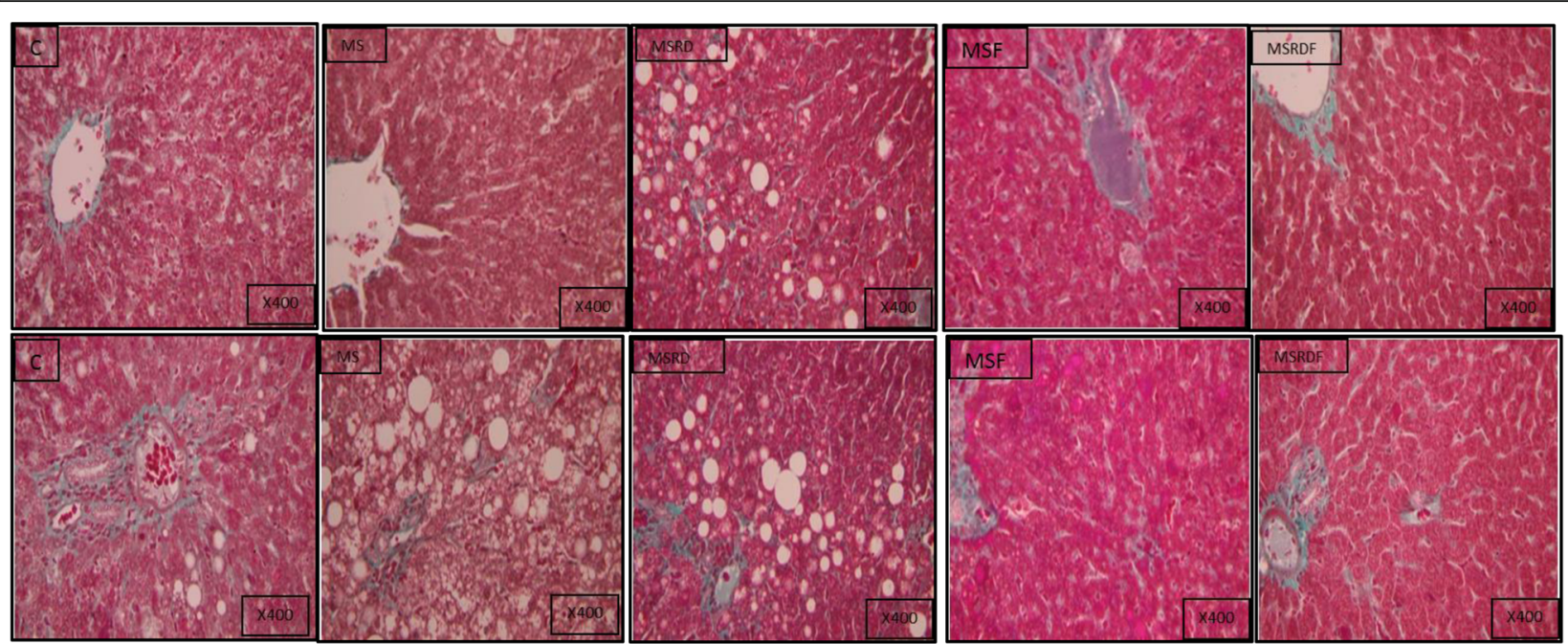

Fig. 10 Liver tissue photomicrograph of the five study groups after 12 weeks (MTS). C control group, MS untreated metabolic syndrome group, MSRD metabolic syndrome group reverted to regular rat chow, MSF metabolic syndrome group on alternate day fasting, MSRDF metabolic syndrome group reverted to regular rat chow and on alternate day fasting

rats. In support, histological studies revealed progression of their liver fatty changes from 69 to $82 \%$ and hepatocyte ballooning score from to 2 with presence of Mallory bodies. Accordingly, the results of MS group at the end of the study indicate that metabolic perturbation induced by high fructose intake is the determinant of NAFLD disease rather than the MetS criteria.

Nutritional intervention, in the present study, namely cessation of fructose intake without caloric restriction in MSRD group, and ADF with continued fructose intake in MSF group resulted in significant amelioration of insulin resistance (serum insulin and HOMA-IR), and dyslipidemia compared to MS rats. The long-term glycemic control parameter (HbA1C) in both groups was declined versus MS rats, approached the control value in both groups and became lower than the normal cutoff value $(<5.7 \%)$ according to American diabetes association [51], in MSF group. Such improved glucose homeostasis was further supported by the significant decrease in FBG level at the end of the study versus the 8th week value in

Table 7 Scoring of fatty change (FC score) and grading of NAFLD in the five study groups

\begin{tabular}{|c|c|c|c|c|c|c|c|}
\hline \multirow{2}{*}{\multicolumn{2}{|c|}{$\begin{array}{l}\text { FC score } \\
1<(5 \%) \\
2(5-33 \%) \\
3(34-66 \%) \\
4>(66 \%\end{array}$}} & \multirow[t]{2}{*}{$\begin{array}{l}\text { Portal } \\
\text { Fibrosis } \\
\text { (PF: 0-6) }\end{array}$} & \multicolumn{4}{|l|}{$\begin{array}{l}\text { Activity score } \\
\text { (AS: } 0-12 \text { ) }\end{array}$} & \multirow{2}{*}{$\begin{array}{l}\text { Grade of NAFLD } \\
\text { Grade } 1 \text { (PF: } 0-2 \\
\text { and AS: } 0-4) \text {, } \\
\text { Grade } 2 \text { (PF: } 3 \text { or } \\
\text { AS: } 5-7) \text { and } \\
\text { Grade } 3 \text { (PF: } 4-6 \text { or } \\
\text { AS: } 8-12 \text { ). }\end{array}$} \\
\hline & & & $\begin{array}{l}\text { Lobular Inflammation and } \\
\text { Necrosis } \\
\text { (LIN: } 0-3 \text { ) }\end{array}$ & $\begin{array}{l}\text { Mallory } \\
\text { Bodies } \\
\text { (MB: 0-3) }\end{array}$ & $\begin{array}{l}\text { Hepatocyte } \\
\text { Ballooning } \\
\text { (HB: } 0-3 \text { ) }\end{array}$ & $\begin{array}{l}\text { Perisinusoidal } \\
\text { Fibrosis } \\
\text { (PSF: } 0-3 \text { ) }\end{array}$ & \\
\hline \multicolumn{8}{|l|}{$\begin{array}{l}8^{\text {th }} \\
\text { week }\end{array}$} \\
\hline (C) & $1(0 \%)$ & & & & & & \\
\hline (M) & $\begin{array}{l}4 \\
(69 \%)\end{array}$ & 0 & 1 & 0 & 1 & 0 & $\begin{array}{l}\text { Grade } 1 \text { (PF: } 0 \text { and } \\
\text { AS: 2) }\end{array}$ \\
\hline \multicolumn{8}{|l|}{ Final } \\
\hline (C) & $1(0 \%)$ & & & & & & \\
\hline (MS) & $\begin{array}{l}4 \\
(82 \%)\end{array}$ & 0 & 1 & 1 & 2 & 0 & $\begin{array}{l}\text { Grade } 1 \text { (PF: } 0 \text { and } \\
\text { AS: 4) }\end{array}$ \\
\hline (MSRD) & $\begin{array}{l}3 \\
(42 \%)\end{array}$ & 0 & 1 & 1 & 1 & 0 & $\begin{array}{l}\text { Grade } 1 \text { (PF: } 0 \text { and } \\
\text { AS: 3) }\end{array}$ \\
\hline (MSF) & $\begin{array}{l}3 \\
(42 \%)\end{array}$ & 0 & 1 & 0 & 0 & 0 & $\begin{array}{l}\text { Grade } 1 \text { (PF: } 0 \text { and } \\
\text { AS: 1) }\end{array}$ \\
\hline $\begin{array}{l}\text { (MSRD } \\
\text { F) }\end{array}$ & $1(0 \%)$ & & & & & & \\
\hline
\end{tabular}


both MSRD and MSF groups. Alleviation of insulin resistance and dyslipidemia for 4 weeks, herein, contributed to interruption of the pathogenic circuits that lead to oxidative stress and inflammation, as evidenced by the significant decrease in liver MDA, as well as serum CRP, in both groups versus MS rats, resulting in regression of fatty change and abatement of hepatocyte ballooning. Such remarkable effect was able to significantly relive $\mathrm{LW}, \mathrm{LW} / \mathrm{BW}$, liver injury (decreased ALT), and improve liver function (increased albumin) in both groups versus MS group. Moreover, hepatic steatosis and steatohepatitis were decreased in both groups versus MS rats as demonstrated by the histological studies.

PAS staining of MSRD livers showed increased PAS +ve glycogen granules in zone 1 vacuolated hepatocytes which infer improved insulin resistance in this zone compared to MS group. However, the absence of PAS +ve glycogen granules from zone 3 of MSRD rat livers was in contrast with MS rat livers and might be attributed to either reversal of metabolic zonation of hepatocytes with reversion to regular diet, reversal of insulin resistance with zone 3 hepatocytes becoming more resistant to glycogenic actions of insulin and zone 1 more sensitive to glycogenic actions of insulin with enhanced glucose uptake and glycogenesis in zone 1 . The exact changes in oxygen gradient, nutrient flow, and expression of different genes in metabolic syndrome-associated NAFLD should be thoroughly investigated before suggesting a plausible explanation of this alteration in hepatic zonation with reversion to regular diet.

MSF hepatocytes showed no PAS +ve glycogen granules throughout the hepatic lobule which might be attributed to enhanced glycogenolysis and suppressed glycogenesis due to the fasting-associated hormonal changes, an observation that was also seen in the MSRD F rat livers.

Thus, both diet regimens, in the current work, were able to attenuate the metabolic derangement induced by HFD, alleviating liver damage, hepatic steatosis, steatohepatitis, and conserve liver function. It seems likely that both diet regimens used in the current work, equally and positively affected the insulin resistance, long-term glycemic control, dyslipidemia, serum albumin, and CRP as proved by the non-significant changes in these parameters between MSRD and MSF groups. However, ADF was more effective in lowering the liver oxidative stress and mitigating the hepatocellular damage than reversion to regular rat diet, as manifested by the significant decrease in liver MDA and ALT levels along with a lower score of Mallory bodies as well as hepatocyte ballooning in MSF group versus MSRD rats.

Additionally, at the end of the study, the overall obesity parameters (BW) and the visceral obesity parameters (WC) were significantly higher than their matched 8th week values in MSRD group. Also, these parameters together with VFW and VFW/BW were not significantly affected in MSRD group versus controls at the end of the study. These findings indicate that cession of fructose for 4 weeks without caloric restriction neither affected the overall obesity nor the visceral obesity. On the contrary, zero-caloric-intermittent fasting with continued fructose intake, herein, was not only able to significantly decrease the overall and visceral obesity parameters in MSF group at the end of the study period versus their matched values at 8 th week, but also, it significantly decreased both in MSF group compared to MS group and MSRD group, becoming even significantly lower than controls. These observations agree with Wan et al. [52], Yang et al. [19], Marinho et al. [53], and Munhoz et al. [54], and denote that caloric restriction by ADF strongly decreased obesity whether overall or visceral, despite the presence of fructose in diet, exceeding the effect of complete cession of fructose in MSRD group. These observations are consistent with Munhoz et al. [54] who found a 35\% decrease in total caloric intake and $20.35 \%$ decrease in body weight gain after 12 weeks of ADF in rats.

It is to be noted that reversion to regular rat diet or ADF for 4 weeks did not completely abolish the increase in insulin resistance, dyslipidemia, liver oxidative stress, ALT, and the decrease in albumin induced by HFD during the first 8 weeks of the study period as their levels in both MSRD and MSF groups were still significantly different from those of control rats. Likewise, the hepatic steatosis and steatohepatitis did not normalize in both groups. A longer duration of nutritional intervention might be required for full correction if each diet regimen was applied individually.

Combination of ADF and reversion to regular rat diet resulted in a synergistic impact on glucose homeostasis parameters, leading to a significant decrease in FBG in MSRDF group versus the MS, MSRD, and MSF group, becoming even significantly lower than controls. This was associated with a remarkable enhancement of glucose clearance with improved glucose tolerance as shown by the significant lower AUC in MSRDF group versus both MSF group and control rats. Furthermore, insulin resistance (HOMA-IR) and long-term glycemic control (HbA1C) were normalized in MSRDF group, as both parameters approached the control values.

Furthermore, the parameters of overall obesity and visceral obesity were diminished significantly in MSRDF group compared to MS, MSRD, and control groups. Additionally, combination of the 2 diet regimens significantly improved all lipid profile parameters and attenuated dyslipidemia, liver oxidative stress compared to MS and MSRD rat groups, with CRP and serum albumin still comparable to MSRD group. This was further clarified 
by the histopathological study of MSRDF rats' livers which revealed resolution of steatosis with FC scorezero and cure of steatohepatitis. Data of these rats indicate that fasting with reversion to normal diet could cure grade-1 NAFLD. Dyslipidemia was also alleviated in MSRDF group versus MSRD and MSF groups, only TC and LDL-C reached the normal control values, while TG was still significantly higher, and HDL-C was significantly lower. The incomplete correction of lipid parameters in MSRDF to control values might explain the failure of the 2 diet regimens in this group to fully ameliorate the liver oxidative stress, hence the serum albumin level was still significantly lower.

Also, of interest was the non-significant changes in obesity parameters, liver MDA, and ALT between MSF and MSRDF group despite their significant decrease in MSRDF versus MSRD group, indicating that caloric restriction by ADF rather than reversion to regular rat diet is responsible for (a) mediating obesity lowering effect and (b) alleviating liver oxidative stress and liver injury in MSRDF group. These observations support our previous assumption that ADF regimen has a dominant effect in alleviating obesity, liver oxidative stress, and liver injury compared to reversion to regular rat diet.

Unpredictably, control rats, in the present study, have developed some features of the MetS on the 8th week, and according to the diagnostic criteria of harmonizing definition of Alberti et al. [1], they were found to have 2 criteria out of 3 needed for MetS diagnosis (low HDL-C $37.7 \mathrm{mg} / \mathrm{dl}$ and high FBG glucose $100.5 \mathrm{mg} / \mathrm{dl})$. Also, at the end of the study, control rats presented a significantly higher WC versus their matched 8th week value together with high FBG $($ FBG $>100 \mathrm{mg} / \mathrm{dl}$ ). These changes might be explained by age progression according to Ghezzi et al. [55] who concluded that the aging process induced metabolic disturbances in Wistar rats and that mature rats (12 months old) showed a significant increase in $\mathrm{BW}$, adiposity, hyperglycemia, as well as dyslipidemia compared to young rats. The absence of liver steatosis in control rats, herein, as demonstrated by the histopathological studies makes the diagnosis of MetS in these rats inappropriate according to Panchal and Brown [56] who included liver dysfunction as a MetS criterion for the animal model of MetS to be validated.

This study has some limitations including lack of caloric intake estimation and lack of fasting control group. Also, it would be of value to determine the local inflammatory response in the liver tissue by estimating TNF- $\alpha$ and/or TGF- $\beta$, and that histopathological study was done for 2 rats in each group and not for all rats which made correlation study between NAFLD grading criteria and other parameters inapplicable.

\section{Conclusion}

Nutritional interventions by ADF or reversion to regular diet improved glucose homeostasis as well as lipid parameters equally; however, ADF has a greater favorable influence on overall and visceral obesity as well as on liver oxidative stress and hepatocellular damage. Combination of the two regimens is more effective in abating metabolic disturbances, hepatic steatosis, steatohepatitis, and liver injury than each regimen separately. Combination of fructose abstinence and ADF may be used as an effective combination approach for curing grade-1 NAFLD associated with metabolic syndrome.

\section{Abbreviations}

ADF: Alternate-day fasting; Alb.: Serum albumin; ALT: Alanine transferase; AUC: Area under the curve; BMI: Body mass index; BW: Body weight; C: Control group; CRP: C-reactive protein; FBG: Fasting blood glucose level; H\&E: Hematoxylin and eosin; HbA1C: Glycosylated hemoglobin; HDL-C: Highdensity lipoprotein cholesterol; HFD: High fructose diet; HFI: High fructose intake; HOMA-IR: Homeostasis model assessment of insulin resistance; IMF: Intermittent fasting; Ins:: Serum insulin; IPGTT: Intraperitoneal glucose tolerance test; LDL-C: Low-density lipoprotein cholesterol; L-MDA: Liver tissue malondialdehyde; LW/BW: Liver weight/body weight ratio; LW: Liver weight; m: Months; M: Metabolic syndrome group; MDA: Malondialdehyde; MetS: Metabolic syndrome; MS: Untreated metabolic syndrome group; MSF: Metabolic syndrome group on alternate-day fasting; MSRD: Metabolic syndrome group reverted to regular rat chow; MSRDF: Metabolic syndrome group reverted to regular rat chow and on alternate-day fasting; NAFL: Nonalcoholic fatty liver; NAFLD: Non-alcoholic fatty liver disease; NASH: Nonalcoholic steatohepatitis; PAS: Periodic acid-Schiff; PG: Peak glycaemia; TC: Serum total cholesterol; TGs: Serum triglycerides; VFW/ BW: Visceral fat weight/body weight ratio; VFW: Visceral fat weight; VLDL: Very low-density lipoproteins; WC: Waist circumference

\section{Acknowledgements}

Not applicable.

\section{Authors' contributions}

NG had performed a fundamental contribution to the design in this study by constructing the experimental protocol. She had followed the experimental plan and involved in the statistical analysis of results. She had included in the writing and final revision of the manuscript. SE had participated in the statistical analysis of results and in the writing of the manuscript. GM had involved in the histological analysis in the study. RM had supervised the experimental work and shared in the writing of the manuscript. MA had carried out the experimental work and assisted in the statistical analysis of results and in the writing of the manuscript. The authors read and approved the final manuscript.

\section{Funding \\ The study was not funded.}

\section{Availability of data and materials}

The datasets used and analyzed during the present work are obtainable from the corresponding author on rational demand.

\section{Declarations}

Ethics approval and consent to participate

This study was performed according to the guidelines of FMASU, REC, Cairo, Egypt, which conforms to the Guide for the Care and Use of Laboratory Animals published by the US National Institute of Health (NO. FWA 00017585).

Consent for publication Not applicable. 


\section{Competing interests}

The authors declare that they have no competing interests.

\section{Received: 8 April 2021 Accepted: 11 June 2021} Published online: 03 July 2021

\section{References}

1. Alberti KG, Eckel RH, Grundy SM, Zimmet PZ, Cleeman JI, Donato KA, Fruchart JC, James WP, Loria CM, Smith SC (2009) Harmonizing the metabolic syndrome: a joint interim statement of the International Diabetes Federation Task Force on Epidemiology and Prevention; National Heart, Lung, and Blood Institute; American Heart Association; World Heart Federation; International Atherosclerosis Society; and International Association for the Study of Obesity. Circulation 120(16):1640-1645

2. Benedict M, Zhang X (2017) Non-alcoholic fatty liver disease: an expanded review. World J Hepatol 9(16):715-732. https://doi.org/10.42 54/wjh.v9.i16.715

3. Carr RM, Oranu A, Khungar V (2016) Nonalcoholic fatty liver disease: pathophysiology and management. Gastroenterol Clin N Am 45(4):639-652. https://doi.org/10.1016/j.gtc.2016.07.003

4. Dietrich P, Hellerbrand C (2014) Non-alcoholic fatty liver disease, obesity and the metabolic syndrome. Best Pract Res Clin Gastroenterol 28(4):637653. https://doi.org/10.1016/j.bpg.2014.07.008

5. Sayiner M, Koenig A, Henry L, Younossi ZM (2016) Epidemiology of nonalcoholic fatty liver disease and nonalcoholic steatohepatitis in the United States and the rest of the world. Clin Liver Dis 20(2):205-214. https:// doi.org/10.1016/j.cld.2015.10.001

6. Kanwar P, Kowdley KV (2016) The metabolic syndrome and its influence on nonalcoholic steatohepatitis. Clin Liver Dis 20(2):225-243. https://doi.org/1 0.1016/j.cld.2015.10.002

7. Hellerbrand C (2010) Pathophysiological similarities and synergisms in alcoholic and non-alcoholic steatohepatitis. Dig Dis 28(6):783-791. https:// doi.org/10.1159/000324286

8. Vernon G, Baranova A, Younossi ZM (2011) Systematic review: the epidemiology and natural history of non-alcoholic fatty liver disease and non-alcoholic steatohepatitis in adults. Aliment PharmacolTher 34(3):274285. https://doi.org/10.1111/j.1365-2036.2011.04724.x

9. Chalasani N, Younossi Z, Lavine JE, Diehl AM, Brunt EM, Cusi K, Charlton M, Sanyal AJ (2012) The diagnosis and management of non-alcoholic fatty liver disease: practice Guideline by the American Association for the Study of Liver Diseases, American College of Gastroenterology, and the American Gastroenterological Association. Hepatology 55(6):2005-2023. https://doi. org/10.1002/hep.25762

10. Calzadilla BL, Adams LA (2016) The natural course of non-alcoholic fatty liver disease. Int J Mol Sci 17

11. Guilherme A, Virbasius JV, Puri V, Czech MP (2008) Adipocyte dysfunctions linking obesity to insulin resistance and type 2 diabetes. Nat Rev Mol Cell Biol 9(5):367-377. https://doi.org/10.1038/nrm2391

12. Cusi $K$ (2009) Role of insulin resistance and lipotoxicity in non-alcoholic steatohepatitis. Clin Liver Dis 13(4):545-563. https://doi.org/10.1016/j.cld.2 009.07.009

13. Pappachan JM, Babu S, Krishnan B, Nishal C, Ravindran NC (2017) Nonalcoholic fatty liver disease: a clinical update. Journal of Clinical and Translational Hepatology 5:384-393

14. Marriott BP, Cole N, Lee E (2009) National estimates of dietary fructose intake increased from 1977 to 2004 in the United States. J Nutr 139:1228s1235 s

15. Ter Horst KW, Serlie MJ (2017) Fructose consumption, lipogenesis, and nonalcoholic fatty liver disease. Nutrients 9(9):981. https://doi.org/10.3390/ nu9090981

16. Yilmaz Y (2012) Review article: fructose in non-alcoholic fatty liver disease Aliment PharmacolTher 35(10):1135-1144. https://doi.org/10.1111/j.1365-203 6.2012.05080.x

17. Park S, Yoo KM, Hyun JS, Kang S (2017) Intermittent fasting reduces body fat but exacerbates hepatic insulin resistance in young rats regardless of high protein and fat diets. J Nutr Biochem 40:14-22

18. Gotthardt JD, Verpeut JL, Yeomans BL, Yang JA, Yasrebi A, Roepke TA, Bello NT (2016) Intermittent fasting promotes fat loss with lean mass retention, increased hypothalamic norepinephrine content, and increased neuropeptide Y Gene expression in diet-induced obese male mice. Endocrinology 157(2):679-691. https://doi.org/10.1210/en.2015-1622
19. Yang W, Cao M, Mao X, Wei X, Li X, Chen G, Zhang J, Wang Z, Shi J, Huang H, Yao X, Liu C (2016) Alternate-day fasting protects the livers of mice against high-fat diet-induced inflammation associated with the suppression of Toll-like receptor 4/nuclear factor KB signaling. Nutr Res 36:586-593

20. Varady KA, Allister CA, Roohk DJ, Hellerstein MK (2010) Improvements in body fat distribution and circulating adiponectin by alternate-day fasting versus calorie restriction. J Nutr Biochem 21(3):188-195. https://doi.org/10.1 016/j.jnutbio.2008.11.001

21. Patel J, lyer A, Brown L (2009) Evaluation of the chronic complications of diabetes in a high fructose diet in rats. Indian J Biochem Biophys 46(1):6672

22. Bahgat NM, Abd-El Rahman AM, Ahmed MA, Megahed GK, Abdel Wahed DM, Ali RH (2017) Study of criteria of metabolic syndrome in young female Albino rats on high fructose intake. Ain Shams Medical Journal 68(1):2-3

23. Zhang M, Lv XY, Li J, Xu ZG, Chen L (2008) The characterization of high-fat diet and multiple low-dose streptozotocin induced type 2 diabetes rat model. Exp Diabetes Res 2008 Article ID 704045, 9 pages

24. Matthews JN, Altman DG, Campbell MJ, Royston P (1990) Analysis of serial measurements in medical research. Bmj. 300(6719):230-235. https://doi. org/10.1136/bmj.300.6719.230

25. Bernardis LL (1970) Prediction of carcass fat, water and lean body mass from Lee's nutritive ratio in rats with hypothalamic obesity. Experientia 26(7):789-790. https://doi.org/10.1007/BF02232553

26. Panchal SK, Poudyal H, lyer A, Nazer R, Alam A, Diwan V, Brown L (2011) High-carbohydrate, high-fat diet-induced metabolic syndrome and cardiovascular remodeling in rats. J Cardiovasc Pharmacol 57(5):611-624 https://doi.org/10.1097/FJC.0b013e31821b1379

27. Fassati p. and prencipe L. (1982) Serum triglycerides determined colorimetrically with an enzyme that produces hydrogen peroxide. clin. Chem 28:2077-2080

28. Tietz N (ed) (1976) Fundamentals of Clinical Chemistry. W.B. Sauders Co, Philadelphia

29. Young D.S. (2001): Effects of diseases on Clinical Lab. Tests 4thadAACC.

30. Doumas B.T. and Biggs H.G. (1976): Standard methods of clinical chemistry, Academic Press, N.Y.7(175).

31. Rand RN, Di Pasqua A (1962) A new diazo method for determination of bilirubin. Clin. Chem 8(6):570-578

32. Golub M (1964) An automated method for determination of serum bilirubin. Clin.Chem 10(5):399-405. https://doi.org/10.1093/clinchem/10.5.399

33. Henry RJ (1964) Clinical chemistry, principles and technics. Harper and Row Publishers, NewYork

34. Satoh K (1978) ClinicaChimica Acta 90:37

35. Ohkawa H, Ohishi W, Yagi K (1979) Anal Biochem 95:351

36. Friedewald WT, Levy RI, Fredrickson DS (1972) Estimation of the concentration of low-density lipoprotein cholesterol in plasma, without use of the preparative ultracentrifuge. Clin Chem 18(6):499-502. https://doi. org/10.1093/clinchem/18.6.499

37. Matthews D, Hosker J, Rudenski A, Naylor B, Treacher D, Turner R (1985) Homeostasis model assessment: insulin resistance and B-cell function from fasting plasma glucose and insulin concentrations in man. Diabetologia 28(7):412-419. https://doi.org/10.1007/BF00280883

38. Burns C, Morris T, Jones B, Koch W, Borer M, Riber U, Bristow A (2010) Proposal to initiate a project to evaluate a candidate International Standard for Human Recombinant Insulin. WHO/BS/10.2143 - Working document QAS/10.381

39. Frishman D, Ardito DM, Graham SM (1992) Performance of glucose monitors. Lab Med 23:3

40. Mendler MH, Kanel G, Govindarajan S (2005) Proposal for a histological scoring and grading system for non-alcoholic fatty liver disease. Liver Int 25: 294-304 r Blackwell Munksgaard 2005

41. Armitage P, Berry G (1987) Statistical methods in medical reserve in left ventricular hypertrophy. Hypertension 5:192-197

42. Garralda-Del-Villar M, Carlos-Chillerón S, Diaz-Gutierrez J, Ruiz-Canela M, Gea A, Martínez-González MA, Bes-Rastrollo M, Ruiz-Estigarribia L, Kales SN, Fernández-Montero A (2018) Healthy lifestyle and incidence of metabolic syndrome in the SUN Cohort. Nutrients. 11(1):65. https://doi.org/10.3390/ nu11010065

43. Mattson MP, Allison DB, Fontana L, Harvie M, Longo VD, Malaisse WJ, Mosley M, Notterpek L, Ravussin E, Scheer FA, Seyfried TN, Varady KA, Panda $S$ (2014) Meal frequency and timing in health and disease. Proc Natl Acad Sci U S A 111(47):16647-16653 cited in Rossman MJ, LaRocca TJ, Martens 
CR, Seals DR. Healthy lifestyle-based approaches for successful vascular aging. J Appl Physiol (1985). 2018;125(6):1888-1900

44. Mckeown NM, Meigs JB, Liu S, Saltzman E, Wilson PW, Jacques PF (2004) Carbohydrate nutrition, insulin resistance, and the prevalence of the metabolic syndrome in the Framingham Offspring Cohort. Diabetes Care 27(2):538-546. https://doi.org/10.2337/diacare.27.2.538

45. Pot G, Hardy R, Stephen A (2014) Irregular consumption of energy intake in meals is associated with a higher cardiometabolic risk in adults of a British birth cohort. Int J Obes 38(12):1518-1524. https://doi.org/10.1038/ijo.2014.51

46. Pot G, Hardy R, Stephen A (2016) Irregularity of energy intake at meals: prospective associations with the metabolic syndrome in adults of the 1946 British birth cohort. Br J Nutr 115(2):315-323. https://doi.org/10.1017/ S0007114515004407

47. Ganesan K, Habboush Y, Sultan S (2018) Intermittent fasting: the choice for a healthier lifestyle. Cureus. 10(7):e2947. https://doi.org/10.7759/cureus.2947

48. Taskinen MR, Packard CJ, Borén J (2019) Dietary fructose and the metabolic syndrome. Nutrients. 11(9):1987

49. Di Luccia B, Crescenzo R, Mazzoli A, Cigliano L, Venditti P, Walser JC et al (2015) Rescue of fructose-induced metabolic syndrome by antibiotics or faecal transplantation in a rat model of obesity. PLoS One 10(8):e0134893

50. Mamikutty N, Thent ZC, Haji SF (2015) Fructose-drinking water induced nonalcoholic fatty liver disease and ultrastructural alteration of hepatocyte mitochondria in male Wistar rat. Biomed Res Int 2015:895961

51. American Diabetes Association (2010) Diagnosis and classification of diabetes mellitus. Diabetes care 33(Suppl 1):S62-S69

52. Wan R, Ahmet I, Brown M, Cheng A, Kamimura N, Talan M, Mattson MP (2010) Cardioprotective effect of intermittent fasting is associated with an elevation of adiponectin levels in rats. J Nutr Biochem 21(5):413-417. https://doi.org/10.1016/j.jnutbio.2009.01.020

53. Marinho TDS, Ornellas F, Barbosa-da-Silva S, Mandarim-de-Lacerda CA, Aguila MB (2019) Beneficial effects of intermittent fasting on steatosis and inflammation of the liver in mice fed a high-fat or a high-fructose diet. Nutrition 65:103-112

54. Munhoz AC, Vilas-Boas EA, Panveloski-Costa AC, Leite JSM, Lucena CF, Riva P. Emilio H, Carpinelli AR (2020) Intermittent fasting for twelve weeks leads to increases in fat mass and hyperinsulinemia in young female Wistar rats. Nutrients 12(4):1029. https://doi.org/10.3390/nu12041029

55. Ghezzi AC, Cambri LT, Botezelli JD, Ribeiro C, Dalia RA, de Mello MA (2012) Metabolic syndrome markers in wistar rats of different ages. Diabetol Metab Syndr 4(1):16. https://doi.org/10.1186/1758-5996-4-16

56. Panchal SK, Brown L (2011) Rodent models for metabolic syndrome research. J Biomed Biotechnol 2011:351982

\section{Publisher's Note}

Springer Nature remains neutral with regard to jurisdictional claims in published maps and institutional affiliations.

\section{Submit your manuscript to a SpringerOpen ${ }^{\circ}$ journal and benefit from:}

- Convenient online submission

- Rigorous peer review

- Open access: articles freely available online

- High visibility within the field

- Retaining the copyright to your article

Submit your next manuscript at $\boldsymbol{\nabla}$ springeropen.com 